\title{
RESUMOS
}

\author{
FÓRUM DE \\ DESENVOLVIMENTO \\ REGIONAL E MEIO \\ AMBIENTE - POLÍTICA, \\ LEGISLAÇÃO E GESTÃO \\ AMBIENTAL
}


OFórum de Desenvolvimento Regional eMeio Ambiente, organizado pelo Programa de Mestrado em Desenvolvimento Regional e MeioAmbiente do Centro Universitário de Araraquara - Uniara, foi realizado em novembro de 2008, com o objetivo de analisar a natureza e a dinâmica de processos de desenvolvimento regionaise locais, sem excluir perspectivas analíticas de âmbito nacional. Foram discutidas condições em que novos espaços e agentes públicos e privados são criados e como as empresas de bense serviços internalizam questões ambientais, sociais e econômicas demandadas pela sociedade. $\mathrm{O}$ Fórum ocorreu em dois dias: no primeiro foi realizada uma mesa-redonda sobre o tema "Políticas Públicas e Meio Ambiente", com a participação dos pesquisadores: Profa. Dra. Luciana Togeiro de Almeira (Unesp/Araraquara), Maria Leonor R. C. L. Assad (UFSCar) e Tamás Szmrecsányi(Unicamp); no segundo, pela manhã, foi realizada uma mesa-redonda sobre o tema "Empresa e Sustentabilidade" com a participação dos pesquisadores: Prof. Dr. Charbel José Chiappetta Jabbour (USP/Ribeirão Preto), Profa. Dra. Maria José Brito Zakia, Profa. Dra. Sonia Valle Walter Borges de Oliveira (USP/ Ribeirão Preto)e Rodrigo Junqueira Barbosa Campos (Instituto ETHOS ). No período da tarde, em uma sessão de painéis foram apresentados e discutidos 58 trabalhos contemplando os seguintes eixos temáticos: Políticas Públicas, Legislação e Desenvolvimento; Gestão empresarial, Inovação e Meio Ambiente; Planejamento e GestãoAmbiental; Agricultura e Desenvolvimento. Cabe destacar o lançamento de dois livros de professores do Programa de Mestrado em Desenvolvimento Regionale Meio Ambiente-Uniara durante o evento: Código de Mineração de 'A' a 'Z', de autoria de Hildebrando Herrmann, Eliane P. R. Poveda e Marcus Vinicius Lopes da Silva, e A propriedade rural como símbolo, de Antônio Ribeiro de Almeida júnior, João Luís de Moraes Hoeffele Oriowaldo Queda.

Oevento contou com 160 participantes, docentes, pesquisadorese alunos de graduação e pós-graduação das universidades da região (UFSCar, USP/São Carlos - Ribeirão Preto, Unesp/Araraquara- Rio Claro-Bauru, Unicamp), assim como funcionários de prefeituras e profissionais da área ambiental.

OFórum de Desenvolvimento Regionale Meio Ambiente buscou ampliar as relações interdisciplinares por meio de discussões conjuntas dos diversos aspectos entre desenvolvimento regionale meio ambiente e, em consequiência, fortalecer o intercâmbio acadêmico-científico entre pesquisadores e instituições envolvidos nesse tema. $\mathrm{O}$ apoio da CAPES foi fundamental para o reconhecimento do esforço do programa em se consolidar como um núcleo dinâmico do conhecimento críticoe científico.

Prof. Dr. DenilsonTeixeira e Profa. Dra. Maria Lúcia Ribeiro, docentes e pesquisadores do Programa de Mestrado em

Desenvolvimento Regional eMeioAmbiente Uniara
The Forum of Regional Development and Environment, organized by the Post Graduate Program in Regional Development and Environment - Uniara was conducted in November 2008 with the objective of analyzing the nature and dynamics of processes of regional and local development, not excluding analytical perspectives in national scope.

The discussions focused on the conditions under which new spaces and public and private agents are created and how companies of goods and services internalize environmental, social and economic issues demanded by society. The Forum took place in two days: in the first, there was a round table on "Public Policy and the Environment", with the participation of researchers: Dr. Luciana Togeiro de Almeira (UNESP/Araraquara), Dr. Maria Leonor R. C. L. Assad (UFSCar) e Dr.Tamás Szmrecsányi (UNICAMP); in the second, in the morning, was performed a round table on the theme "Business and Sustainability" with the participation of researchers: Dr. Charbel José Chiappetta Jabbour (USP/Ribeirão Preto), Dr. Maria José Brito Zakia, Dr. Sonia Valle Walter Borges de Oliveira (USP/Ribeirão Preto) e Rodrigo Junqueira Barbosa Campos (ETHOS Institute ). In the afternoon, in a session of board were presented and discussed 58 papers covering the following themes: Public Policy, Legislation and Development, Business Management, Innovation and Environment, Planning and Environmental Management, Agriculture and Development. It is important to emphasize the launch of two books from teachers of the Masters Program in Regional Development and Environment - Uniara during the event: Mining Code of 'A' to 'Z', authors Hildebrando Herrmann, Eliane P. R. Poveda e Marcus Vinicius Lopes da Silva, and The Rural Property as a Symbol, authors Antônio Ribeiro de Almeida Júnior, João Luís de Moraes Hoeffel e Oriowaldo Queda. The event had 160 participants, among teachers, researchers and graduate and postgraduate students from universities in the region (UFSCar, USP/São Carlos - Ribeirão Preto, UNESP/Araraquara - Rio Claro - Bauru, UNICAMP), as well as officials from municipality and professionals in the environmental area. The Forum of Regional Development and Environment aims to expand the interdisciplinary relations through joint discussions in the various aspects of regional development and environment and, consequently, to strengthen the academic and scientific exchange between researchers and institutions involved in this issue. The support of CAPES was crucial for the recognition of the effort of the program in consolidating as a dynamic core of critical and scientific knowledge.

Dr. Denilson Teixeira and Dr. Maria Lúcia Ribeiro, professor and researcher of the PostGraduate Program in Regional Development and Environment-Uniara 
TRANSPOSIÇÃO DO RIO PIUMHI PARA O RIO SÃO FRANCISCO: REGISTRO HISTÓRICO

ASSIS, André Tomé*; RIOS, Leonardo**

\section{Políticas Públicas}

*Programa de Mestrado em Desenvolvimento Regional e Meio Ambiente, do Centro Universitário de Araraquara - Uniara.

**Docente (Orientador) do Programa de Mestrado em Desenvolvimento Regional e Meio Ambiente do Centro Universitário de Araraquara - Uniara. 


\section{PERCEPÇÕES SOCIOAMBIENTAIS DAPOPULAÇAO PERIURBANA DE ARARAQUARA-SPACERCA DO PROJETO DE SANEAMENTO AMBIENTAL}

\author{
FERREIRA. D. Ap. de O*; NISHIKAWA D.L.**; MAZARI. E.J.***; \\ FANTIN, J.T***; POTTES, M.R. Granhani***
}

O presente trabalho objetiva mostrar a percepção da população periurbana quanto à necessidade de saneamento básico. Para tanto, foram realizados estudos em bairros periféricos situados no município de Araraquara-SP, cuja peculiaridade principalé viver uma realidade mais rural que urbana. Apesar de integrados ao perímetro urbano, tais bairrose um em particular estão organizados na forma de chácaras, que são utilizadas para lazer em finais de semana ou como locais de produção de hortifrutigranjeiros. Outra característica desses bairrosé a ausência de sistemas de saneamento, como água encanada e rede de esgoto. Por meio de uma linha de financiamento do PAC - Programa de Aceleração do Crescimento, esses serviços públicos passarão a ser acessíveis para a população desses bairros. Problemática ainda vigente no Brasil, o saneamento ambiental é hoje uma preocupação em âmbito nacional. Segundo dados do Ministério da Saúde foram 13 mil mortes causadas pelo conjunto de 15 doenças relacionadas ao saneamento ambiental. A falta de saneamento traduz o quadro de exclusão econômica e social em que estámergulhada parcela significativa da população brasileira (www.asseamae.org.br/ 2008). Nesse sentido o trabalho procurou elucidar quais as percepções a comunidade a ser beneficiada pela obra tem do projeto e das questões ambientais relacionadas ao saneamento ambiental nessas áreas. Foram aplicados 429 questionários, de forma direta, com perguntas fechadas e abertas, visando levantar as informações necessárias para o desenvolvimento do projeto. Aspectos relacionados ao Meio Ambiente ganharam uma valorização ao longo do tempo. Foi possível observar na área a ser atendida pelo projeto que a comunidade local possuiuma realidade diferenciada dos moradores daárea urbana. A comunidade deixa claro que compreende a importância da obra na garantia da qualidade de vida tanto no que compete a saúde humana quanto ambiental. Concluímos ainda que essas comunidades têm uma visão crítica das ações públicas.

Palavras-chave: Saneamento Ambiental, Periurbano, Percepção Ambiental.

*Professora Doutora no Programa de Pós-Graduação em Sociologia, Faculdade de Ciências e Letras da Unesp - Araraquara/SP

**Doutoranda no Programa de Pós-Graduação em Sociologia, Faculdade de Ciências e Letras da Unesp Araraquara/SP.

***Graduando em Ciências Sociais da Faculdade de Ciências e Letras da Unesp - Araraquara/SP.

\section{PRESERVAR O PATRIMÔNIO E EDUCAR O CIDADÃO}

VALENTE, Guilherme Eduardo Almeida Prado de Castro*

O artigo tem como objetivo fazer uma análise crítica da implantação da Política Pública de Preservação do Patrimônio Artístico e Cultural da cidade de Jaú, seus desdobramentos e sugestão para sua ampliação através de um programa de Educação Patrimonial. APrefeitura da cidade de Jaú criou o Conselho Municipal de Patrimônio Artístico e Cultural em 2002, com a intenção de criar um mecanismo para a implantação da política pública municipal de preservação do patrimônio arquitetônico construído durante o auge do ciclo cafeeiro. Construções feitas desde a década de 1880 à década de 1920 são bastante significativas no centro de Jaú. São cerca de 300 imóveis, entre casarões, estabelecimentos comerciais e monumentos comemorativos, classificados como de interesse de preservação. Passados seis anos da implantação do Conselho e da mudança das leis para se obter licença de demolição dos imóveis, não houve por parte do governo municipal, nem mesmo da sociedade civil, interesse para a ampliação desta política pública de preservação. Notícias divulgadas na imprensa local foram utilizadas para a elaboração deste texto, que ainda apresenta uma breve revisão sobre conceitos de patrimônio e políticas públicas. Nota-se que a falta da ampliação da política pública de preservação ocasionou a percepção negativa por parte dos comerciantes da área central, que a vêem como uma política de engessamento do progresso, devido ao impedimento de demolições dos prédios antigos. Para que haja mudança nessa concepção, é necessária a ampliação da política de preservação, através de um projeto que contemple a Educação Patrimonial. Segundo Maria de Lourdes Parreira Horta (1999), é necessário um processo educativo para educar o olhar da população com relação ao seu patrimônio material e imaterial. Horta classifica em quatro etapas a implantação da Educação Patrimonial: observação, registro, exploração e apropriação, que quando aplicadas podem contribuir com a visualização de pontos positivos na preservação do centro.

Palavras-chave: Educação Patrimonial, Preservação, Política Pública.

\footnotetext{
*Aluno do Programa de Mestrado em Desenvolvimento Regional e Meio Ambiente do Centro Universitário
} de Araraquara - Uniara. 


\section{O ESTUDO DO MEIO COMO FERRAMENTA NA EDUCAÇÃO}

BERGAMASCO, Roberta Gandolfi Franzini*

O objeto deste estudo é a verificação da metodologia estudo do meio, se a mesma tem sido utilizada em escolas do município de Catanduva e se alcança função de destaque na prática docente, de modo a auxiliar no processo de ensinoaprendizagem. Analisa-se a contribuição na formação de cidadãos e na formulação de uma conscientização e valorização dos bens biológicos, patrimoniais, culturais entre outros. O trabalho realiza-se em quatro instituições escolares do município de Catanduva e leva em consideração os Parâmetros Curriculares Nacionais. Existe a análise do significado da metodologia na formulação de uma postura educacional voltada à conservação ambiental e também verifica se a utilização dessa metodologia produz efeitos significativos para estudantes e professores. Observa-se a apropriação dessa técnica ou metodologia por parte do professorado e também se, ao final da utilização da mesma, o ensino se tornou mais ou menos prazeroso para os alunos. Há também a averiguação de: até que ponto existem projetos de estudo do meio nos Projetos Políticos Pedagógicos e se existe a produção de interdisciplinaridade com sua utilização e, portanto, se existe como resultado a conscientização ambiental. Evidencia-se que o estudo do meio não se relaciona à simples obtenção de informações fora da sala de aula ou à simples constatação de conhecimentos já elaborados, encontrados em livros didáticos, enciclopédias ou jornais, que se pode verificar in loco na paisagem humana ou geográfica. O estudo do meio envolve uma metodologia de pesquisa e de organização de novos saberes, que requer atividades anteriores à visita, bem como levantamento de questões a serem investigadas, seleção de informações, observações em campo, comparações entre os dados levantados e os conhecimentos já organizados por outros pesquisadores, interpretação, enfim, organização de dados e avaliação. Ao final deste estudo se pretende elaborar um manual para que a prática metodológica seja bem utilizada, ou melhor, que a utilização da metodologia aconteça com responsabilidade e segurança pelos professores e que os alunos realmente obtenham os melhores resultadosem termos de aprendizagem.

Palavras-chave: Estudo do Meio, Educação e Interdisciplinaridade.

*Centro Universitário de Araraquara - Uniara.
EDUCAÇÃO AMBIENTAL COMO PROPOSTA METODOLÓGICA DE AÇÕES EDUCATIVAS NO ENSINO FUNDAMENTAL-II DA REDE PÚBLICA ESTADUAL

ZACHARIAS, Luiz Carlos Júnior*; CINTRÃO, Janaína Florinda Ferri**; FREITAS, Gerson Júnior*; PORTERO, Rosemeire Rogatti*

A Educação Ambiental realizada como Proposta Metodológica de Ações Educativas foi efetivada em Limeira-SP no primeiro semestre de 2008, tendo como objetivo contribuir e tentar promover mudanças em relações às questões ambientais locais através de ações educativas. Os indivíduos envolvidos são alunos da Escola Estadual "Dom Tarcísio Ariovaldo Amaral", localizada em uma área residencial com altos índices de degradação socioambiental. O trabalho centralizou-se nas questões ligadas ao meio ambiente local, sobretudo nas problemáticas da água, do lixo urbano nas imediações da bacia hidrográfica no qual a escola está inserida. A metodologia adotada foi embasada em vários autores ligados às práticas educativas, aplicadas em forma de aulas teóricas e práticas de campo internamente e externamente da unidade escolar, com dinâmicas, apresentações teatrais, vídeo aulas, análises de figuras e mapas da região e confecção de artigos com materiais reciclados. No alcance dos resultados, procurou-se transmitir aos alunos noções básicas de meio ambiente, através de práticas pedagógicas, fazendo com que os conteúdos fossem absorvidos de forma espontânea, buscando principalmente a contextualização local para se entender o regional e o global, assim tentando construir novos multiplicadores de Ações Ambientais, fazendo com que as pessoas transformem seus ambientes locais e possam criar ações conjuntas comunitárias. A perspectiva deste estudo é educar cada vez mais cedo futuras gerações, para uma nova mudança no contexto de Percepção e Conscientização nas diversas áreas do conhecimento ambiental, podendo transformar uma determinada localidade e buscar assim melhoria na qualidade de vida.

Palavras-chave: Educação Ambiental, Alunos, Ações.

*Alunos do Programa de Mestrado em Desenvolvimento Regional e Meio Ambiente do Centro Universitário de Araraquara - Uniara.

**Docente do Programa de Mestrado em Desenvolvimento Regional e Meio Ambiente do Centro Universitário de Araraquara - Uniara. 
UM ESTUDO SOBRE AÇÕES MUNICIPAIS EM DIREÇÃO AO

DESENVOLVIMENTO SUSTENTÁVEL POR MEIO DAANÁLISE DOS 8 OBJETIVOS DO MILÊNIO; OS CASOS DE SÃO CARLOS E IBITINGA

ALVES, Dagoberto*; SILVA, Ethel Cristina Chiari da**; HERMOSILLA, José Luis Garcia**

O presente estudo aborda o conceito do termo desenvolvimento sustentável, discutindo a visão de diversos autores, e investiga as ações dos entes administrativos municipais que contemplem aquilo que se define como sustentável (tripé socioeconômico-ambiental), norteando-se para tal análise pelos 8 objetivos do milênio - (1) Erradicar a extrema pobreza e a fome; (2) Atingir o ensino básico universal; (3) Promover a igualdade entre os sexos e a autonomia das mulheres; (4) Reduzir a mortalidade infantil; (5) Melhorar a saúde materna; (6) Combater o HIV/AIDS, a malária e outras doenças; (7) Garantir a sustentabilidade ambiental; (8) Estabelecer uma parceria mundial para o desenvolvimento. Destacam-se na pesquisa as ações sobre a educação e meio ambiente. Para o desenvolvimento do trabalho, primeiro realizou-se uma pesquisa bibliográfica, seguido de uma pesquisa de campo - as informações foram coletadas por meio de entrevistas e análise de documentos. A pesquisa envolveu os municípios de São Carlos e Ibitinga. Concluiu-se que, em São Carlos, todas as ações levantadas demonstram estar contemplando requisitos dos 8 objetivos do milênio e que, nos objetivos 2 e 7, o município se destaca; tal afirmação se baseia em dados documentais coletados. Já em Ibitinga, identificou-se que existem carências e que, em alguns momentos, há ausência de ações ligadas a alguns dos 8 objetivos - por exemplo, nos objetivos 3 e 8, e no 2 e no 7 pouco se articulou. Porém, nos objetivos 1, 4 e 5, as ações desenvolvidas são altamente satisfatórias, servindo de modelo para outros municípios. Por fim, observou-se que, em ambos os casos, existem significativos avanços em direção à implementação de ações que possam satisfazer os pré-requisitos para o alcance dos 8 objetivos do milênio.

Palavras-chave: Desenvolvimento Sustentável, Administração Pública, Oito Objetivos do Milênio.

*Aluno do Programa de Mestrado em Desenvolvimento Regional e Meio Ambiente do Centro Universitário de Araraquara - Uniara.

**Docentes do Programa de Mestrado em Desenvolvimento Regional e Meio Ambiente do Centro Universitário de Araraquara - Uniara.

\section{DESCONCENTRAÇÃO PRODUTIVA NA INDÚSTRIA AERONÁUTICA EM DIREÇÃO À REGIÃO ADMINISTRATIVA CENTRAL DO ESTADO DE SÃO PAULO}

OLIVEIRA, Fernando Bueno*; PAULINO, Sônia Regina**

O objetivo do trabalho é analisar a instalação da indústria aeronáutica na Região Administrativa Central (RAC). No caso brasileiro, a dinâmica da cadeia produtiva setorial, fortemente internacionalizada, reduziu a importância dos fornecedores de base local, o que coloca dificuldades para o adensamento da cadeia produtiva de base nacional. O enfrentamento desse quadro aponta a necessidade de fortalecimento da rede local e das relações de cooperação com vistas à reversão do processo de enfraquecimento do papel do sistema de inovação local no desempenho competitivo da indústria. $\mathrm{O}$ trabalho busca identificar elementos presentes na região que a qualifique para uma inserção dinâmica, dada pela integração em sistemas de inovação, desse novo eixo concentrador de investimentos ligados ao setor em foco. Foram realizadas pesquisa qualitativa e análise descritiva. O levantamento de informações contou com a aplicação de questionário considerando três categorias de atores locais: (i) ligados à formação e treinamento de recursos humanos; (ii) ligados às atividades empresariais de produção e manutenção de aeronaves; (iii) e órgão público ligado ao governo municipal. Como atividades ligadas à inovação realizadas na RAC, são identificadas aquelas relacionadas aos projetos de modernização de aeronaves do segmento de defesa, à montagem de aeronaves experimentais, que serão utilizadas nos ensaios e testes, e às atividades de ensaios em vôo propriamente ditas. Considerando elementos estratégicos na indústria aeronáutica, os desafios para a inserção da RAC no sistema de inovação são ao menos de duas ordens: consolidarse como fonte de recursos humanos qualificados e explorar o potencial existente na infra-estrutura de ciência e tecnologia presente na região.

Palavras-chave: Sistema de Inovação, Indústria Aeronáutica, Desenvolvimento Local.

\footnotetext{
*Centro Universitário de Araraquara - Uniara; Universidade Paulista - Unip-Araraquara.
} **Centro Universitário de Araraquara - Uniara. 


\section{ABORDAGEM DOS RESÍDUOS DE SERVIÇO DE SAÚDE: ANÁLISE DA GRADE CURRICULAR DE UM CURSO TÉCNICO DE ENFERMAGEM}

SERAPHIM, Carla Regina Ulian Manzato*; RIBEIRO, Maria Lúcia**

Os problemas referentes ao manejo dos resíduos de serviço de saúde (RSS) e da preservação ambiental representam um desafio a ser alcançado por todos os setores da sociedade. Um caminho para solucionar as questões de manuseio e tratamento dos resíduos sólidos de serviço de saúde é principalmente o treinamento dos profissionais da área da saúde que, ao cumprirem seu papel de multiplicadores e educadores, conseguem propor mudanças e soluções. Nesse sentido, os profissionais da equipe de enfermagem (Enfermeiro, Técnico e Auxiliar de Enfermagem) devem conhecer e compreender os conceitos teóricos e práticos que envolvem os procedimentos de manuseio e tratamento dos resíduos gerados por suas atividades na assistência direta ao paciente. Considerando a relevância desses dados, é importante conhecer como o tema RSS vem sendo abordado na formação dos profissionais Auxiliares e Técnicos de Enfermagem, de forma a preparálos e instrumentalizá-los a exercer suas atividades com concepção ética de responsabilidade e comprometimento com a qualidade de vida do ambiente. O presente estudo está sendo desenvolvido no curso Técnico de Enfermagem da escola ETEC Prof a "Anna de Oliveira Ferraz", selecionada entre as quatro escolas técnicas de Araraquara, por ser aquela que vem oferecendo este curso há 40 anos, atendendo à forte demanda do mercado de trabalho. Entrevistas abertas com o diretor e o coordenador foram realizadas abordando, entre outros, os seguintes aspectos: objetivos dos cursos, perfil do profissional de conclusão, grade curricular e Plano de Ensino das disciplinas que discutem o assunto RSS. Os resultados mostraram que o tema RSS foi introduzido na grade curricular somente a partir de 2005, contemplando quatro disciplinas. A análise do plano de ensino aponta para fragmentação e falta de articulação dos conteúdos dos RSS entre as disciplinas; este pode ser um dos motivos que vêm impossibilitando os alunos de estabelecer relações entre os conceitos ensinados e as ações vivenciadas nos estágios supervisionados (Técnico deEnfermagem) e na sua atuação profissional(Auxiliar de Enfermagem).

Palavras-chave: Resíduos de Serviço de Saúde, Curso Técnico de Enfermagem, Grade Curricular.

*Centro Universitário de Araraquara - Uniar

**Docente do Programa de Mestrado em Desenvolvimento Regional e Meio Ambiente do Centro Universitário de Araraquara - Uniara.
ORGANIZAÇÕES NÃO-GOVERNAMENTAIS AMBIENTAIS NA UNIDADE DE GERENCIAMENTO HÍDRICO DOS RIOS TURVO E GRANDE: ENTRE A RESISTÊNCIA E A UTOPIA

TAVARES, Jussara da Silva*; FERRANTE, Vera Lúcia Silveira Botta**

Este trabalho tem como objetivo central a compreensão e análise da eficácia da atuação ambiental das Organizações Não-Governamentais que estão inseridas na região da Bacia Hidrográfica dos rios Turvo e Grande, e suas relações com os demais atores que militam nesse campo interativo. A opção pelas ONGs ambientais regionais inseridas na Unidade de Gerenciamento em Recursos Hídricos - UGRH15, que corresponde à região da Bacia Hidrográfica dos rios Turvo e Grande, se justifica para entendimento do que está sendo construído nesses espaços regionais relativo à questão ambiental, visto que existem muitos estudos sobre a atuação das grandes ONGs nacionais e transnacionais, mas é praticamente desconhecida a atuação dessas entidades fora dos grandes centros. Após mapear as ONGs ambientais regionais, procedemos a pesquisa direta junto a essas entidades. Alguns dados foram obtidos por meio de fontes primárias e fontes secundárias e utilizamos a revisão bibliográfica para entendimento de alguns aspectos teóricos relacionados ao Terceiro Setor, às ONGs e à democracia participativa. As ONGs têm respondido às demandas ambientais de seu entorno, contribuindo para uma reflexão sobre formas de organização e participação popular e meio ambiente. Nesse sentido, participam do levantamento de dados para o diagnóstico da situação atual dos recursos hídricos e estabelecimento de diretrizes técnicas para a elaboração do Plano de Bacia Hidrográfica do Turvo Grande - Relatório Zero e outros. Também desenvolvem ações regionais/locais de Educação Ambiental e promovem o reflorestamento/ revegetação de parte de mata ciliar e proteção de nascentes. Aatuação das ONGs ambientais regionais apresenta evidências de que é possível a superação/mitigação dos agravos ambientais, pois elas têm desempenhado o papel de protagonistas do processo de transformação social, com representatividade e competência para agregar pessoas, instituições e recursos em defesa do meio ambiente.

Palavras-chave: Meio Ambiente, Participação Popular, ONGs.

*Aluna do Programa de Mestrado em Desenvolvimento Regional e Meio Ambiente do Centro Universitário de Araraquara - Uniara.

**Docente do Programa de Mestrado em Desenvolvimento Regional e Meio Ambiente do Centro Universitário de Araraquara - Uniara. 
LEVANTAMENTO HISTÓRICO E FLORÍSTICO DA PRAÇA MAESTRO TESCARI NO MUNICÍPIO DE ARARAQUARA-SP

RESTAINO, Éder Carlos*; PAPA, Douglas Murilo Abrahão*; SOSSAE, Flávia Cristina**; GERALDO, João Carlos***

Desde as primeiras cidades, na região da Mesopotâmia, atual Irã e Iraque, o homem alterou o ambiente para construir suas habitações e edificações. Entre essas construções e edificações ocorriam espaços, ora planejados ou não, que serviam para a circulação humana e convívios sociais, chamados de espaços livres públicos, onde as pessoas tinham acesso e se reuniam para festas, encontros, convivência e outras práticas de atividades. No Brasil, os jardins surgiram no final do século XIX com a moda vinda da Europa, tendo como influência a introdução de espécies exóticas na arborização. A partir das décadas de 1920 e 1930, Burle Marx inovou a flora nos espaços urbanos com a utilização de espécies nativas. Atualmente, com o grande crescimento urbano e degradação das áreas naturais, o homem volta a procurar as áreas naturais, ambientes arborizados e com paisagem mais agradável para viver, morar e frequientar. O objetivo do trabalho foi realizar o levantamento histórico e florístico da Praça Maestro Tescari (Praça da Igreja Matriz) em Araraquara-SP. O levantamento histórico foi baseado em pesquisas e consultas em acervos históricos e o estudo florístico restringiu-se às espécies vegetais que constituem toda a quadra da praça e seu entorno. A praça foi construída pelo fundador da cidade entre 1805 e 1808 e recebeu o nome atual apenas em 1908, como homenagem ao Maestro Tescari. O levantamento florístico contabilizou 79 espécies pertencentes a angiospermas e gimnospermas; destas, 22 espécies são nativas e 56, exóticas. Dentre as espécies estudadas destacamos a murta eugenia (Eugenia sprengellii), a latania vermelha (Latania commersonii), a seafórtia (Archontophoenix alexandreae) e palmeira real (Roystonea oleraceae).

Palavras-chave: Levantamento Florístico, Levantamento Histórico, Espaços Públicos.
AVALIAÇÃO DAS EFICÁCIAS E ENTRAVES DO PLANO ACIONAL DE EDUCAÇÃO NOS ESPAÇOS LOCAIS

BIANCARDI, Luciane Maria Jayme*

O presente estudo pretende demonstrar que a eficácia e os entraves das metas relacionadas ao Plano Nacional de Educação ganham contornos diferenciados nos espaços locais, que se apresentam com perfis próprios, com características específicas nos aspectos de gestão política, cultural, econômico, social, entre outros. A comprovação ou refutação dessa hipótese pode ser aferida, até então, apenas por meio dos resultados do IDEB (Índice de Desenvolvimento da Educação). Portanto, apesar das leis, metas e normas, o ambiente institucional tem condições específicas dos locais, tem variáveis analíticas locais que interferem e são determinantes na análise dessas aplicabilidades, da eficácia, bem como dos entraves. Acredita-se que essas ações específicas são mais relevantes, existindo, portanto, outros indicadores de diagnóstico e avaliação locais.

Inicialmente, o presente trabalho discorre historicamente sobre o plano nacional de educação e analisa criticamente o processo avaliatório pelo IDEB. Contextualizase sobre metodologias de avaliação de políticas públicas e apresenta os primeiros indicadores de diagnósticos locais.

Palavras-chave: Políticas Públicas, Plano Nacional de Educação, IDEB, Indicadores de Diagnósticos Locais.

*Centro Universitário de Araraquara - Uniara

**Programa de Mestrado em Desenvolvimento Regional e Meio Ambiente e do Curso de Ciências Biológicas do Centro Universitário de Araraquara - Uniara.

***Curso de Turismo e Hotelaria do Centro Universitário de Araraquara - Uniara. 


\section{EXPERIÊNCIA PARTICIPATIVA EM CONSELHOS DELIBERATIVOS DE POLÍTICAS: O CASO DO CONSELHO MUNICIPAL DE SAÚDE DE ITÁPOLIS-SP}

\author{
BRUNALDI, Cassíria*; LORENZO, Helena Carvalho de**
}

Com a Constituição de 1988, o Estado centralizado se desregulamentou, possibilitando que níveis subnacionais participassem das decisões sobre políticas no interior de espaços participativos institucionalizados, fortalecendo o poder local. No caso da política de saúde, uma característica foi a formação nos municípios de redes locais de saúde, que elaboram políticas resultantes da articulação de interesses entre atores locais. Esses atores estão organizados em conselhos municipais de saúde, funcionando como espaços participativos que influenciam nas decisões. Apesar de serem espaços de diálogo entre governo e sociedade, apresentam limites no que se refere à capacidade de os atores sociais influenciarem nas decisões. Essas influências participativas foram analisadas neste trabalho por meio de um estudo de caso que objetiva conhecer o papel do Conselho Municipal de Saúde de Itápolis-SP na política de saúde local e, especificamente, caracterizar os atores sociais que o compõem, identificar seus recursos de poder, caracterizar seu funcionamento e organização. A metodologia foi um estudo exploratório e qualitativo, realizando-se pesquisa secundária e de campo com entrevistas semi-estruturadas com os atores locais. Os resultados apontam para a força do segmento do governo municipal, que detém mais recursos de poder, sendo os temas da pauta determinados por ele e levados ao conselho para aprovação, que ocorre por consenso prévio sem debates participativos, observando uma nítida dependência dos demais segmentos em relação ao governo. Embora o estudo esteja em andamento, pôde-se detectar a fragilidade da rede municipal, em que uma efetiva participação dos atores no conselho está relacionada a uma mudança no seu comportamento, que deve ser mais democrático.

Palavras-chave: Conselhos, Política de Saúde, Redes, Participação.

*Aluna do Programa de Mestrado em Desenvolvimento Regional e Meio Ambiente do Centro Universitário de Araraquara - Uniara.

**Docente do Programa de Mestrado em Desenvolvimento Regional e Meio Ambiente do Centro Universitário de Araraquara - Uniara.
AÇÕES DE COMUNICAÇÃO AMBIENTAL NO MUNICÍPIO DE CATANDUVA NA GESTÃO 2004-2008

OLIVIO, Dennis Henrique Vicário*; FERRANTE, Vera Lúcia Silveira Botta**

Nos últimos anos, pôde-se constatar o crescente aumento do número de ações ambientais promovidas pelos diversos setores da sociedade, bem como a eminente participação da indústria da propaganda na divulgação dessas ações. Diante desse panorama, este resumo tem como objetivo levantar as ações de comunicação promovidas pelo município de Catanduva na gestão 2004-2008 e, entre elas, identificar as ações de âmbito ambiental. O processo metodológico teve seu início através do levantamento, junto à Secretaria de Comunicação do município, das ações de comunicação da Prefeitura de Catanduva na gestão 2004-2008. Aopção pelo período vem de encontro ao crescimento da temática ambiental em todos os setores sociais nos últimos anos. Além disso, a administração pública do município de Catanduva nessa gestão promoveu uma série de mudanças significativas para a cidade, e utilizou os meios midiáticos para divulgar essas ações. Constatou-se que no período levantado foram realizadas 752 ações publicitárias. Desse total, apenas 8 tiveram fins puramente ambientais. Outras ações, apesar de margearem os propostos ambientais, foram excluídas do estudo devido a fatores como: abrangência (campanhas de nível nacional), tipologia (ações de saúde pública - dengue) e categoria (campanhas de ordem institucional). Diante dos resultados, pode-se afirmar que o poder público municipal ainda não atentou sobre a importância de seu trabalho como agente disseminador da consciência ambiental, assim como os demais segmentos da sociedade. Dessa forma, não desenvolve programas de longo prazo e, na maioria das vezes, apenas promove ações de âmbito denunciativo e penalizador.

Palavras-chave: Publicidade, Meio Ambiente, Poder Público Municipal.

*Aluno do Programa de Mestrado em Desenvolvimento Regional e Meio Ambiente do Centro Universitário de Araraquara - Uniara

**Docente do Programa de Mestrado em Desenvolvimento Regional e Meio Ambiente do Centro Universitário de Araraquara - Uniara. 


\section{POLÍTICAS PÚBLICAS DE DESENVOLVIMENTO SUSTENTÁVEL DO APL - CALÇADOS FEMININOS DE JAÚ-SP. GERENCIAMENTO DE RESÍDUOS INDUSTRIAIS}

MASSAN, Tiago Agostini*; CONTADOR, Osvaldo Junior**; CASTRO, Marcus Cesar Avezum Alves de ***

A importância de políticas públicas no atual cenário é de extrema pertinência, seja para promover a atuação do governo nas áreas em que existam falhas, como, por exemplo, saúde, meio ambiente e educação, ou na análise dessas ações, propondo mudanças. O gerenciamento de resíduos industriais tornou-se relevante para a promoção do desenvolvimento sustentável. Com o objetivo de mostrar a importância das políticas públicas para o gerenciamento de resíduos sólidos industriais, foram elencadas as propostas de políticas públicas sugeridas pelo grupo de trabalho de política ambiental do Arranjo Produtivo Local de Jaú-SP, adotadas pela Prefeitura Municipal. Os dados foram obtidos por meio de levantamento dos estudos realizados e entrevistas com os autores desses estudos. Os resultados do levantamento elaborado foram as proposições de políticas públicas, tais como: Certificado de Aprovação para Destinação de Resíduos Industriais e envio dos resíduos para o aterro Sanitário de Paulínia-SP; centro de transbordo e envio dos materiais para o aterro e outras alternativas comerciais; parcerias no processo de reciclagem do couro e uso da tecnologia de produção mais limpa. Ficou claro que as políticas públicas podem provir dos outros setores da sociedade civil para suprir falhas do setor público. As políticas sugeridas pelo grupo de trabalho do arranjo produtivo local foram acatadas e estão em fase de implementação por parte do poder público.

Palavras-chave: Políticas Públicas, Resíduos, Produção Mais Limpa.

\section{A RESERVA FLORESTAL LEGAL E OS PRINCÍPIOS CONSTITUCIONAIS DA ISONOMIA E RAZOABILIDADE}

OLIVEIRA, André Luiz*; ZAKIA, Maria José Brito*

A legislação florestal no Brasil é encarada por muitos como uma limitação ao direito de propriedade, especialmente em relação à obrigatoriedade da chamada Reserva Florestal Legal nas propriedades rurais. Esse diploma legal determina que todas as propriedades localizadas no Estado de São Paulo devem reservar o percentual de $30 \%$ de sua área com mata nativa. O trabalho objetiva analisar a legislação florestal no que tange à instituição da Reserva Legal e seus impactos causados aos pequenos e médios proprietários rurais, com vistas à aplicação dos princípios constitucionais da isonomiae razoabilidade. Para isso foi feita uma pesquisa de natureza exploratória, com análise jurídico-dogmática da legislação ambiental, além de pesquisa de campo entre pequenos e médios proprietários rurais do município de Natividade da Serra-SP. A inexistência de uma legislação que contemple as diversas fitofisionomias existentes nos variados cenários agrícolas faz com que o Código Florestal incida de maneira genérica, sem contemplar as especificidades de cada região, gerando distorções ao princípio constitucional da igualdade material, que pressupõe que, para efeito de aplicação da norma legal, quem se encontre em uma situação desigual deve ser tratado de forma diferente, porém, na medida exata de suas desigualdades. O Código Florestal Brasileiro falha como norma geral ao regular de maneira idêntica situações diferentes, fazendo com que uma mesma norma incida sobre regiões que possuem características diversas, gerando reflexos especialmente nos pequenos e médios produtores rurais. Cabe, portanto, a criação de uma política florestal que atenda ao princípio da igualdade material, contemplando as características da região onde a norma surtirá o seu efeito.

Palavras-chave: Direito, Reserva Legal, Código Florestal, Isonomia, Proporcionalidade.

\begin{abstract}
*Programa de Mestrado em Desenvolvimento Regional e Meio Ambiente do Centro Universitário de Araraquara - Uniara

**Mestre pelo Programa de Mestrado em Desenvolvimento Regional e Meio Ambiente do Centro Universitário de Araraquara - Uniara. Docente da Faculdade de Tecnologia - Fatec de Jaú.

***Docente do Programa de Mestrado em Desenvolvimento Regional e Meio Ambiente do Centro Universitário de Araraquara - Uniara.
\end{abstract}

REVISTA UNIARA, $n .^{0}$ 21/22, 2008/2009
* Programa de Mestrado em Desenvolvimento Regional e Meio Ambiente, Centro Universitário de Araraquara - Uniara, Araraquara/SP 
POLÍTICAS PÚBLICAS COM PERSPECTIVA DE

DESENVOLVIMENTO TERRITORIAL E COESÃO SOCIAL: CONTEXTUALIZAÇÃ O E FORMAÇÃO DAS REDES LOCAIS DE SEGURANÇAALIMENTAR

\section{ALMEIDA, Luiz Manoel*}

Inicialmente, foi realizada uma discussão teórico-metodológica sobre o objeto deste trabalho, as políticas públicas com perspectiva de desenvolvimento territorial. Tomaram-se como base os estudos teóricos da nova territorialização e a articulação com o processo continuado de avaliação e aprimoramento de políticas públicas. Discorreu-se historicamente sobre a problemática da reestruturação agroindustrial, que agravou a problemática da insegurança alimentar da população carente mundial e a exclusão social de atores produtivos (pequenos agricultores familiares) dos circuitos produtivos globais. Foram analisadas as possibilidades de formação de redes de segurança alimentar como instrumentos de desenvolvimento nos espaços locais ou regionais. Apresentou-se a metodologia de identificação da Escala Brasileira de Insegurança Alimentar (EBIA) e avaliou-se o nível de Insegurança alimentar de cada município selecionado nas suas áreas urbanas e rurais, abrindo brechas analíticas com outras variáveis. Nas considerações finais, desenvolveram-se indicadores de resultados e de impactos da implementação das políticas locais de segurança alimentar, bem como uma proposta metodológica de aplicação e de mensuração desses indicadores.

Palavras-chave: Políticas Públicas, Segurança Alimentar, Desenvolvimento Local, Eficácia.

\section{LOGÍSTICA REVERSA DE LÂMPADAS FLUORESCENTES NO}

\section{MUNICÍPIO DE JAÚ-SP}

FERREIRA, Homero Vicente*; CAPPS, Ana Luiza Almeida Prado*; NAVARRO, Everton Checheto*

Anualmente 70 milhões de lâmpadas fluorescentes são descartadas no Brasil. Essas lâmpadas, ao serem quebradas, liberam mercúrio metálico, metal altamente tóxico para o ser humano e o meio ambiente, causando acumulações ao longo da cadeia alimentar. Apesar de insignificante o efeito de uma lâmpada no meio ambiente, a somatória pode causar danos sensíveis no local em que for descartada. O presente trabalho tem a finalidade de conscientizar a população para o descarte adequado de lâmpadas fluorescentes. Para solucionar o problema, as empresas que comercializam o produto foram orientadas pela Secretaria de Meio Ambiente a recolher as lâmpadas. Além disso, foi realizada junto à população uma campanha, com palestras e panfletos educativos, sobre a destinação adequada das lâmpadas fluorescentes. Todo material recolhido foi armazenado na Secretaria de Meio Ambiente. A coleta é de competência da APLIQUIM, que faz a reciclagem e a destinação adequada dos resíduos. O projeto teve início em agosto de 2008 e, desde a sua implantação, foram recolhidas e destinadas de forma adequada 16 mil lâmpadas, aproximadamente 1066 lâmpadas por mês. Para cada lâmpada fluorescente tubular quebrada no meio ambiente, é liberado $0,015 \mathrm{~g}$ de mercúrio metálico. Com a implantação do sistema de recolhimento de lâmpadas no município, aproximadamente $240 \mathrm{~g}$ desse material foram destinados corretamente, correspondendo ao trabalho de conscientização.

Palavras-chave: Lâmpada Fluorescente, Logística Reversa, Mercúrio Metálico, Contaminação.
*Docente do Programa de Mestrado em Desenvolvimento Regional e Meio Ambiente do Centro Universitário de Araraquara - Uniara. Faculdade de Engenharia Agrícola da Unicamp.
*Secretaria de Meio Ambiente de Jaú-SP 


\section{A LEGISLAÇÃO ESTADUAL PAULISTA E O INCENTIVO AO DESENVOLVIMENTO DAATIVIDADE TURÍSTICA}

FINO, Patrícia*; QUEDA, Oriowaldo**

O governo do estado de São Paulo (Constituição Estadual de 1967) criou o termo "Estância", visando atender e impulsionar a demanda efetiva e potencial dos municípios classificados com essa denominação. Esses municípios são contemplados com recursos financeiros que devem ser utilizados para promover melhorias em sua infra-estrutura e serviços turísticos, de acordo com a necessidade de seus visitantes. Com isso, se torna fundamental discutir a eficiência desse tipo de concessão. O presente trabalho tem como objetivo contribuir para essa análise, utilizando como universo analítico a Estância Turística de Salto. Esse município recebeu o título de Estância em setembro de 1999, após aprovação em todas as etapas do processo jurídico. Para realização desta pesquisa foi necessária a realização de revisão bibliográfica e levantamento documental. Perante análise do processo que transformou Salto em Estância Turística, foi possível constatar inúmeras ineficiências e irregularidades. Grande parte das exigências listadas como fundamentais pela legislação e pelos órgãos competentes (CONDEPHAAT - Conselho de Defesa do Patrimônio Histórico, Artístico, Arqueológico e Turístico e DADE - Departamento de Apoio ao Desenvolvimento das Estâncias) não foi cumprida pelo município. Diante dos resultados observados nesta pesquisa, é possível afirmar que Salto não possuía os requisitos considerados essenciais. Desta forma, não poderia ter se transformado em Estância Turística. Esta constatação nos leva a uma série de indagações e nos abre uma ampla agenda de pesquisa.

Palavras-chave: Turismo, Legislação Estadual, São Paulo, Salto.
INVENTÁRIO DOS TEMAS E AUTORES NA ÁREA DE TURISMO E MEIO AMBIENTE

BARBOSA, Alex Sandro*;TEIXEIRA, Denilson**

O turismo e o meio ambiente se inter-relacionam de maneira incontestável, já que o meio ambiente constitui a "matéria-prima" da atividade turística. Assim, éfundamental o bom relacionamento entre eles, já que a sobrevivência do turismo depende da sua conservação. O objetivo principal deste projeto foi inventariar os temas e autores na área de turismo e meio ambiente, suas pesquisas e lacunas existentes neste campo de pesquisa. A formação do banco de dados para as análises se deu por meio da identificação e seleção dos trabalhos entre 1987 e 2006, a partir do banco de teses da Coordenação de Aperfeiçoamento de Pessoal de Nível Superior (CAPES), utilizando para a busca as seguintes palavras-chave: turismo e meio ambiente, turismo e ambiente, turismo ambiental, turismo sustentável, turismo de aventura, turismo e educação ambiental e ecoturismo. A base está organizada sob os seguintes aspectos: caracterização geral, análises disciplinar, temática, autores e procedimentos metodológicos. O inventário é formado por 63 teses: a pesquisa científica, segundo a base consultada, teve início em 1993 e o pico de produção foi em 2002, com 14 teses defendidas. AUniversidade de São Paulo (USP) foi a que mais produziu teses, com 27 trabalhos $(42,9 \%)$. As universidades paulistas produziram juntas 42 teses, se destacando entre os demais estados e contribuindo para a Região Sudeste liderar a defesa de teses, com 73\% (46 trabalhos). A Fundação Getúlio Vargas (FGV) é a única instituição privada com 2 teses defendidas em turismo e meio ambiente. A produção científica na área está aumentando gradativamente, porém concentrada na Região Sudeste e em universidades públicas.

Palavras-chave: Turismo, Meio Ambiente, Base de Dados.

*Aluno do Programa de Mestrado em Desenvolvimento Regional e Meio Ambiente do Centro Universitário de Araraquara - Uniara.

**Docente do Programa de Mestrado em Desenvolvimento Regional e Meio Ambiente do Centro Universitário de Araraquara - Uniara. 
CONFLITOS NAAPLICAÇÃO DA POLÍTICAAMBIENTAL NA ZONA DA MATA MINEIRA

BERNARDO, William Fernandes*; MUNIZ, José Norberto**

O presente estudo procura descrever e compreender a legislação ambiental brasileira com a especificidade de sua aplicação na Zona da Mata Mineira, região montanhosa e farta em recursos hídricos. Esses elementos naturais fazem com que as normas ambientais sejam muito restritivas, especialmente quando se considera a presença significativa de pequenos produtores rurais no local. Foi realizada pesquisa bibliográfica para compreender (a) o marco legal da legislação ambiental a partir de sua história no Brasil, (b) os papéis do Estado na elaboração e execução desse conjunto de leis específicas e (c) os embates na aplicação das normas legais na Zona da Mata Mineira. O trabalho identifica o conflito na execução da atual legislação ambiental brasileira em três esferas: a do produtor rural, a quem cabe o ônus da proteção, mas não recebe a devida compensação; a das instâncias do Estado, responsáveis pelo cumprimento das normas legais, mas incapazes de exercer seu mandato, seja por suas ineficiências, seja quando relevam os danos ambientais em benefício do interesse social; e a da população (especialmente urbana), que se beneficia da proteção ambiental e exige o cumprimento da legislação. A inadequação da atual legislação ambiental para a Zona da Mata Mineira pode explicar, ao menos em parte, o não cumprimento dos dispositivos legais, tanto pelos produtores rurais como pelos próprios agentes do Estado. As características naturais e sociais da região demandam um arranjo diferenciado na legislação ambiental de forma a dividir o ônus e os benefícios entre produtores rurais e a população.

Palavras-chave: Política ambiental; Zona da Mata Mineira; Conflito.
O TRABALHO DO JOVEM APRENDIZ: UMA PROMESSA INSTITUCIONAL TRUNCADA

SGARBI, Luciani Marconi Caetano Martins*

Considerando que a Lei 10.097/00 tem por escopo a formação do adolescente através do seu desenvolvimento cultural e profissional e sua inserção no contexto social do trabalho, com enfoque formativo prioritariamente ao produtivo, pretendese contrapor aludido diploma legal com a realidade, analisando-se as possibilidades legais e as dificuldades reais. A princípio foi necessária uma pesquisa bibliográfica para compreender a significação da infância, da adolescência e do trabalho. Por meio dessa pesquisa se apurou, também, que no Brasil o trabalho infanto-juvenil sempre está diretamente ligado à condição socioeconômica da família. O universo empírico escolhido, a cidade de Ibitinga, é um pólo da indústria têxtil e do bordado, setor econômico relacionado historicamente a esse tipo de trabalho. Os dados que possibilitam verificar se a maneira e os critérios usados na aplicação da lei são eficazes estão sendo obtidos por meio de entrevistas e questionários semi-estruturados, abordando, dentre outros, os seguintes aspectos: perfil da família do aprendiz e a significação do curso no cotidiano familiar, postura adotada (aceitação e rejeição) por todos os atores envolvidos na sua aplicação. As respostas aos questionários aplicados até o momento demonstraram que os jovens inseridos no programa têm uma visão positiva sobre o curso, pois, segundo eles, o conteúdo trabalhado cria uma perspectiva promissora em relação ao futuro sob os aspectos profissional, educacional e pessoal. Tais resultados são parciais e a complexidade da questão social necessita de outros instrumentos que serão utilizados para a busca da verdadeira compreensão desta realidade.

Palavras-chave: Jovem Aprendiz, Trabalho Infanto-Juvenil, Aprendizagem, Lei $10.097 / 00$
*Mestrando em Extensão Rural no Departamento de Economia Rural da Universidade Federal de ViçosaMG e analista da Embrapa Gado de Leite.

**Professor-titular do Departamento de Economia Rural da Universidade Federal de Viçosa-MG.
*Aluna do Programa de Mestrado em Desenvolvimento Regional e Meio Ambiente do Centro Universitário de Araraquara - Uniara. 


\section{ESTUDO DA POLUIÇÃO ATMOSFÉRICA POR MATERIAL PARTICULADO EM SUSPENSÃO E PARTÍCULAS INALÁVEIS EM PEDÁGIO DE RODOVIA, 2007}

MATTOSO*, Clarissa Caximiliano; TERAN*, Francisco Javier Cuba

\section{Gestão}

\section{Empresarial}

Nos dias atuais, há uma grande preocupação com os poluentes que são lançados no meio ambiente. Com isso surge a necessidade de se estudar com mais acuidade as substâncias que afetam o meio e também prejudicam a saúde humana. A atmosfera não está livre dessas emissões, e este estudo foca o material particulado lançado principalmente por indústrias e por veículos movidos a combustão interna. Para avaliar a quantidade desse material suspenso na atmosfera foi utilizado o Amostrador de Grande Volume para material inalável com tamanho menor a 10 ?m (MP10), que coleta amostras de ar atendendo à Norma ABNT destinada a esse tipo de poluente. O objetivo foi monitorar a presença de material particulado inalável na rodovia Anhangüera, Km 152, de forma a verificar a presença de níveis de poluição atmosférica além do limite estipulado pela legislação ambiental vigente. As amostras foram coletadas semanalmente e em dias estratégicos, como finais de semanas e feriados e também em dias com o tráfego de veículos menos intenso. Em cada ocasião foram seguidas as recomendações indicadas na Norma ABNT NBR 13412 - Material particulado em suspensão na atmosfera - Determinação da concentração de partículas inaláveis pelo método do amostrador de grande volume acoplado a um separador inercial de partículas (ABNT, 1995). A análise dos dados permite identificar que a concentração de MP10 se manteve, em todo o período de coleta, acima do permitido pela legislação vigente CONAMA(Conselho Nacional de Meio Ambiente) n. ${ }^{\circ}$ 03/1990, que limita a concentração de material particulado inalável (MP10) suspenso no ar em 50 ?g/m3 de ar coletado. Com os resultados obtidos, pode-se afirmar que a queda da concentração de MP10 ocorreu em um dia em que a média do fluxo de veículos se manteve baixa e nas altas concentrações não se conseguiu determinar o motivo do seu aumento, por não haver uma caracterização contínua das variáveis, sendo este projeto apenas a primeira parte do estudo.

Palavras-chave: Poluição Atmosférica, Material Particulado, Partículas Inaláveis. 
HISTÓRIA ORAL: UMA PROPOSTA DE PESQUISA DA TEMÁTICA AMBIENTAL

NISHIKAWA, Mario*

O objetivo deste painel é apresentar parte da nossa pesquisa de doutorado, desenvolvida no Programa de Pós-Graduação em Educação Escolar da Faculdade de Ciências e Letras da Unesp-Araraquara. Trata-se da parte que se refere à análise dos depoimentos de educadores que trabalharam na escola pública e mencionaram as suas experiências atuando no movimento ambientalista. Foi realizado um estudo sobre a Experiência do Educador a partir da análise de depoimentos orais de professores da escola pública. Buscamos compreender a questão do Projeto Pedagógico (individual e coletivo) destacando dois temas básicos: o trabalho do professor de ensino fundamental e médio, e a utilização da Temática Ambiental na escola. Nesse sentido, pretende-se apresentar uma proposta metodológica de pesquisa na área da educação ambiental e da temática ambiental, a partir do emprego do termo experiência, no sentido indicado por E.P.Thompson e Walter Benjamin, e da utilização História Oral enquanto técnica de gravação, produção e tratamento de depoimento oral coletado. Pretendemos: mostrar a aplicação de uma proposta de investigação em que se destaca o depoimento oral como fonte primária da pesquisa, demonstrar também como uma proposta metodológica pode revelar um quadro histórico do surgimento das discussões sobre a temática ambiental, e como uma investigação de depoimentos do educador da escola pública aparece como sujeito do processo de introdução da problemática ambiental na escola.

Palavras-chave: Temática Ambiental, Educação Ambiental, História Oral, Experiência.

* Universidade Estadual de Campinas - Unicamp, Limeira/SP.
PRODUÇÃO MAIS LIMPA EM ARRANJOS PRODUTIVOS LOCAIS: O CASO DO PÓLO MOVELEIRO DE VOTUPORANGA

PRADO, Lauro Lodo*; LORENZO, Helena Carvalho de**

A partir da constatação da importância do local para o desenvolvimento econômico e social, vêm se ampliando os estudos sobre Arranjos Produtivos Locais (APLs). No Brasil existem vários grupos que desenvolvem estudos sobre o tema e esses estudos, embora apresentem algumas diferenças conceituais, também apresentam idéias centrais em comum, como proporcionar maior cooperação entre as empresas aí localizadas, condensar a cadeia produtiva, aproximar einserir as empresas do aglomerado em rodadas de negócios, fomentar a importância da atuação de agentes locais direto e de universidades e centros tecnológicos. Porém, em todos esses estudos sobre APLs, a questão ambiental quase nunca é mencionada ou aparece apenas como questão coadjuvante. Frente a esta constatação, a presente pesquisa teve como ponto de partida duas referências conceituais. Em primeiro uma concepção de desenvolvimento como um processo integrado e de longo prazo. Em segundo, a noção de que o desenvolvimento deve considerar a questão ambiental como uma questão intrínseca e sempre presente. Nessa direção o foco prioritário da pesquisa para o estudo dos APLs foi propor a questão ambiental como um aspecto estruturante. O estudo empírico está centrado na identificação das potencialidades e limites dautilização da Produção Limpa $(\mathrm{P}+\mathrm{L})$ em empresas aglomeradas. As evidências empíricas que fundamentaram o estudo tiveram como delimitação o Pólo Moveleiro de Votuporanga. Com relação à abordagem do problema o estudo caracterizou-se como pesquisa exploratória e qualitativa. Foram levantados dados secundários e primários sobre o tema. Oinstrumento escolhido para a coleta dos dados primários foram entrevistas com um roteiro prévio estruturado, em empresas selecionadas. Resultados ainda iniciais mostram que a preocupação com a questão ambiental nas empresas do pólo não ocorre. Algumas razões já podem ser identificadas: o elevado custo de introdução da tecnologia de $\mathrm{P}+\mathrm{L}$ e a falta de percepção dos ganhos coletivos que resultam da introdução das mesmas. Ou seja, a viabilidade do uso de $\mathrm{P}+\mathrm{L}$ somente poderá ocorrer quando os empresários visualizarem ganhos econômicos para a empresa e ou ganhos coletivos.

Palavras-chave: Arranjos Produtivos Locais, Produção Mais Limpa, Pólo Moveleiro de Votuporanga, Desenvolvimento.

\footnotetext{
*Aluno do Programa de Mestrado em Desenvolvimento Regional e Meio Ambiente do Centro Universitário de Araraquara - Uniara.

**Docente do Programa de Mestrado em Desenvolvimento Regional e Meio Ambiente do Centro
} Universitário de Araraquara - Uniara. 


\section{METODOLOGIA E CONSCIENTIZAÇÃO AMBIENTAL PARA IMPLANTAÇÃO DE UM PROGRAMA DE RECICLAGEM DE BITUCA DE CIGARRO EM CENTROS UNIVERSITÁRIOS}

VILELA, Eliana*; MARQUES, Daniela Aparecida Oliveira*

As bitucas de cigarro jogadas inadequadamente geram vários problemas ambientais, tais como: incêndios, entupimentos de esgotos, calhas; provocando a poluição visual, ambiental, acidentes, etc. O presente trabalho destina-se a desenvolver uma metodologia para reciclagem da bituca de cigarro (cuja composição é patenteada), transformando-a em papel, além de promover a conscientização dos alunos da Uniara a respeito dos prejuízos causados pela bituca de cigarro, através da abordagem de alunos e funcionários com a entrega de bituqueiras aos fumantes, e montar pontos de coleta do material. Primeiramente foi coletado o material descartado em locais inadequados para testes de reciclagem; em seguida, foi feita a conscientização por meio da abordagem direta através da distribuição de teasers. Essa técnica é usada em marketing para chamar a atenção para um anúncio no qual não se oferece nenhuma informação sobre o produto em publicitação, levando o público a interrogar-se sobre o significado da peça e despertando curiosidade pela explicação no ambiente da instituição. Em seguida visitamos salas de aula e departamentos dando uma breve explicação sobre o trabalho, pedindo a colaboração dos fumantes para descartar as bitucas nos pontos de coleta espalhados pela instituição. Um questionário com oito questões fechadas foi aplicado para alunos e funcionários com a finalidade de analisar a importância deste projeto e seus benefícios. Após várias tentativas, foi encontrada a metodologia adequada. Na primeira coleta foram obtidas 509,47g de bituca; após a conscientização obtivemos 148,56g. Com esse trabalho conseguimos desenvolver a metodologia para reciclagem da bituca de cigarro e, ao mesmo tempo foi possível diminuir consideravelmente a quantidade de bitucas lançadas nos locais inadequados. Das pessoas questionadas, $98 \%$ estavam cientes do projeto e de acordo com a importância da implantação da coleta seletiva.

Palavras-chave: Bitucas, Conscientização Ambiental, Reciclagem, Coleta Seletiva.

*Centro Universitário de Araraquara - Uniara
UM ESTUDO SOBRE A SUSTENTABILIDADE CORPORATIVA: MODELOS DE MENSURAÇÃO NAS EMPRESAS

ROMANO, André Luiz*; SILVA, Ethel Cristina Chiari da**; HERMOSILLA, José Luís Garcia**

A definição de sustentabilidade pode ser suprir as necessidades da geração atual não prejudicando a capacidade das gerações futuras em atender as suas. Nesse cenário, surgem os indicadores de sustentabilidade como forma de mostrar o que efetivamente deve ser feito, apontando uma visão integrada das inter-relações ambientais, sociais e econômicas. O trabalho consta de um levantamento e uma discussão das bases teóricas de novas sistemáticas de mensuração da sustentabilidade nas empresas. Buscou-se através do levantamento bibliográfico caracterizar o estado da arte do tema, selecionando ferramentas de mensuração da sustentabilidade e verificando as fragilidades no modelo de auditoria, além da análise de seus questionários. Aanálise de algumas das ferramentas de gestão da sustentabilidade corporativa conduz a três de grande relevância e utilização, a saber: a) AA1000 lançada em 1999 pelo Institute of Social and Ethical AccountAbility, é uma ferramentas de gestão, englobando o processo de levantamento de informações e auditoria, com enfoque no diálogo com stakeholders; b) FSC - Forest Stewardship Council - criada em 1993 para promover a gestão responsável das florestas no mundo, aponta quais empresas utilizam o equilíbrio nos recursos florestais, oferecendo aos consumidores a informação que possibilita a escolha de produtos social e ambientalmente responsável; c) O Global Reporting Initiative - surgiu em 1997, desenvolvido pela Coalition for Environmentally Responsible e pelas Nações Unidas. Essa ferramenta busca melhorar a qualidade das informações dos relatórios de sustentabilidade corporativa, através da aplicação de questionários posicionando a empresa. A utilização de uma ferramenta como o questionário difere da auditoria, pois é uma alternativa que apresenta menor risco de manipulação. É uma oportunidade para a empresa mostrar transparência, destacando a sustentabilidade do negócio

Palavras-chave: Sustentabilidade Corporativa, Indicadores de Sustentabilidade e Negócios.

*Aluno do Programa de Mestrado em Desenvolvimento Regional e Meio Ambiente do Centro Universitário de Araraquara - Uniara.

**Docentes do Programa de Mestrado em Desenvolvimento Regional e Meio Ambiente do Centro Universitário de Araraquara - Uniara 


\section{INDICADORES DE DESEMPENHO AMBIENTAL DE INDÚSTRIA DO SETOR SUCROALCOOLEIRO: UM ESTUDO DE CASO}

PAULA, Theodoro José Marcos*; CASTRO, Marcus César Avezum Alves de **

A conciliação das atividades produtivas com a manutenção da qualidade ambiental é o grande desafio das organizações. A redução dos custos decorrentes da gestão ambiental e a conquista de novos mercados com produtos e serviços ambientalmente corretos são diferenciais competitivos para as empresas se manterem no mercado. Assim, o conhecimento dos custos associados ao manejo de resíduos e efluentes gerados em uma empresa é fundamental para estruturar o planejamento estratégico do setor ambiental. Nesse sentido, a pesquisa desenvolvida apresenta os custos relativos ao gerenciamento dos principais resíduos sólidos e efluentes industriais de uma indústria sucroalcooleira, propondo indicadores ambientais como instrumento para monitorar e comparar empresas do mesmo segmento. A pesquisa foi desenvolvida em uma indústria sucroalcooleira localizada na região de Araraquara. Inicialmente foram identificados os pontos de geração de resíduos e efluentes no processo produtivo para, posteriormente, quantificá-los por meio de planilhas. Os resíduos considerados no estudo foram água residuária, bagaço, torta de filtro e vinhaça. Em média, são gastos $\mathrm{R} \$ 4,61 /$ tonelada de cana processada com o manejo dos principais resíduos gerados na indústria sucroalcooleira, o que representa $17,5 \%$ do preço médio da cana praticado no período em análise.

Palavras-chave: Custos Ambientais, Resíduos Sólidos, Efluentes Industriais, Usinas de Açúcar e Álcool.
UTILIZAÇÃO DA BIOMASSA DA CANA-DE-AÇÚCAR COMO FONTE ALTERNATIVA DE ENERGIA

MENEGUELLO, Luiz Augusto*; CASTRO, Marcus Cesar Avezum Alves de **

A produção de energia elétrica a partir da biomassa da cana-de-açúcar é um tema que permeia as discussões sobre fontes alternativas de energia para o Brasil. Entretanto, observa-se que uma parcela muito pequena da energia elétrica produzida comercialmente no Brasil tem na biomassa da cana-de-açúcar a sua fonte primária Nesse sentido, o objetivo do trabalho é apresentar os resultados de pesquisa sobre a utilização atual da biomassa da cana-de-açúcar na produção de energia elétrica pelas usinas de açúcar e álcool do estado de São Paulo e verificar o interesse dos produtores do setor sucroalcooleiro na geração de energia elétrica como uma oportunidade de negócios. Os dados foram coletados por meio da aplicação de questionários às usinas do estado de São Paulo, o que permitiu ao entrevistado manifestar suas opiniões, pontos de vista e argumentos sobre o tema. Os resultados da pesquisa demonstraram que a maioria dos produtores do setor sucroalcooleiro tem interesse na produção comercial de energia elétrica, embora este interesse ainda não se concretize em investimentos nesta atividade. A quase totalidade das usinas que utilizam a biomassa na geração de energia, o fazem com a finalidade de obter créditos de carbono, via Mecanismos de Desenvolvimento Limpo.

Palavras-chave: Cana-de-açúcar, Biomassa, Energia.
*Programa de Mestrado em Desenvolvimento Regional e Meio Ambiente do Centro Universitário de Araraquara - Uniara.

**Professor do Programa de Mestrado em Desenvolvimento Regional e Meio Ambiente do Centro Universitário de Araraquara - Uniara. IGCE-UNESP/Rio Claro. *Programa de Mestrado em Desenvolvimento Regional e Meio Ambiente do Centro Universitário de
Araraquara - Uniara.

**Professor do Programa de Mestrado em Desenvolvimento Regional e Meio Ambiente do Centro Universitário de Araraquara - Uniara. IGCE-UNESP/Rio Claro. 


\section{AS CONDIÇÕES SOCIOECONÔMICAS E CULTURAIS DO \\ PROJETO DE ASSENTAMENTO ESTRELA DA ILHA E A INSERÇÃO DA ECONOMIA SOLIDÁRIA}

ARAUJO, Rosângela Ramos*; SOUZA, Regina Maria*

O projeto tem como intuito fundamental analisar a viabilidade de utilização das práticas típicas de economia solidária como estratégia de geração de oportunidade de trabalho e de renda pelos produtores rurais do assentamento Estrela da Ilha, através das quatro organizações coletivas ali presentes, evidenciando seus aspectos positivos e negativos e ainda verificar como ocorrem os mecanismos de gestão e funcionamento dessas organizações. Na pesquisa, em fase de execução, estão sendo coletadas informações relativas à população estudada: sexo, procedência, faixa etária, nível de escolaridade, renda obtida, recursos do Pronaf, trabalho da família, produtos comercializados e participação em organizações coletivas, numa amostra significativa, através de questionários aplicados junto aos produtores selecionados e entrevistas semi-estruturadas. A economia solidária se baseia na propriedade coletiva ou associada do capital com inclusão do indivíduo no sistema produtivo, por meio de sistemas de autogestão da produção, através de cooperativas populares ou associações. Os indivíduos têm igualdade de direitos, principalmente no que diz respeito aos bens produzidos eliminando os intermediários. A autogestão e cooperação multiplicam-se nos assentamentos rurais sob a forma de associações e cooperativas. Em Ilha Solteira, a partir de 2005, 207 famílias de trabalhadores sem-terra foram assentadas no Assentamento Estrela da Ilha, onde constituíram três organizações coletivas, sendo uma cooperativa e duas associações e, recentemente, uma quarta associação está sendo constituída.

Palavras-chave: Assentados, Economia Solidária, Autogestão, Cooperação, Sistema Produtivo.

\section{Gestão}

\section{Ambiental}

*Fundação Municipal de Educação e Cultura de Santa Fé do Sul-FUNEC. 


\section{O DESENVOLVIMENTO DO TURISMO: UMA VISÃO SISTÊMICA}

BARROS, Marcelo Oliveira*; SILVA, Sibele Castro*
A IMPORTÂNCIADA EDUCAÇÃO AMBIENTAL NOS SERVIÇOS DE SANEAMENTO

OLIVEIRA, Simone Cristina de*

A atividade turística deve ser analisada como um conjunto de amplas relações, apresentando interações com o ambiente econômico, jurídico, social, político, ecológico, tecnológico, entre outros. O turismo está inserido no setor terciário da economia e seu efeito multiplicador compreende um imenso número de empresas, atuando direta e indiretamente no seu desenvolvimento. Quando bem planejado, é gerador de empregos e riqueza, via de intercâmbio cultural, caminho para a conservação das belezas naturais e culturais e gerador de positivas mudanças sociais. Neste contexto, para que o turismo regional brasileiro se desenvolva de forma sistêmica, focando o desenvolvimento endógeno, dando ênfase aos aspectos sociais, culturais, éticos e de desenvolvimento comunitário, estimulando o desenvolvimento local sem abandonar o fator econômico (MARTINELLI e JOYAL, 2004), é preciso integração e interação dos agentes que compõem esse processo, como a iniciativa privada, o poder público e a comunidade local. Essa é a base para o desenvolvimento sustentável do turismo, definido pela OMT - Organização Mundial de Turismo como aquele que atende às necessidades dos turistas e das regiões receptoras e ao mesmo tempo protege e fomenta as oportunidades para o futuro. O desenvolvimento sustentável do turismo se mostra como um caminho para a gestão de todos os recursos de forma que possam satisfazer as necessidades econômicas, sociais e estéticas, respeitando ao mesmo tempo a integridade cultural, os processos ecológicos essenciais, a diversidade e os sistemas que sustentam a vida (DIAS, 2005).

Palavras-chave: Turismo, Visão Sistêmica, Sustentabilidade, Desenvolvimento Econômico.

\footnotetext{
*Centro Universitário de Franca - UniFacef.
} a incluir diretrizes em seu escopo de trabalho que não se limitam apenas ao atendimento básico da população para as demandas de água e coleta e afastamento dos esgotos sanitários. Naturalmente essas mudanças tornaram parte da rotina dos serviços de saneamento, devido às demandas relacionadas ao meio ambiente. $\mathrm{A}$ noção simplista do extrativismo da água para atendimento de necessidades básicas cedeu espaço ao consumo consciente. Desse modo, os prestadores de serviços de saneamento incluíram em suas atribuições a preservação e conservação de mananciais. Associada a esta nova tendência, buscaram respaldo do conhecimento e da metodologia difundida nas ciências humanas, realizando uma intervenção em educação ambiental que possibilitou a interlocução com a comunidade, no sentido de aproximála do gerenciamento dos recursos hídricos. O Departamento Autônomo de Água e Esgotos - DAAE de Araraquara, autarquia municipal responsável em oferecer o serviço de abastecimento público de água e de coleta, afastamento e tratamento dos esgotos domésticos nesta cidade do interior paulista, conquista espaço entre empresas do mesmo ramo e se torna referência no setor ao estabelecer uma aproximação, nos últimos cinco anos, com a sociedade civil, escolas de ensino infantil, fundamental e médio, universidades locais, associações, serviços de saúde pública (PSFe UBS) e comunidade em geral, além das parcerias em projetos estaduais (FEHIDRO) e nacionais (MMA-FNMA-Coletivos Educadores). Desse modo, reforça as tendências defendidas e executadas nos Ministérios das Cidades e do Meio Ambiente para o saneamento ambiental. Utilizando suas instalações (ETA, ETE, ETRS, Represas de Captações e CESAMA) e intervenções na comunidade, o DAAE estabelece diálogos, forma multiplicadores e constrói valores acerca da importância dos recursos hídricos. Muitos projetos estão em andamento e muito ainda há que se aprender e construir; entretanto, o mais importante é romper com as redomas e os preconceitos e propor parâmetros inovadores de gerenciamento no saneamento ambiental viabilizando a interlocução com a comunidade.

Palavras-chave: Educação Ambiental, Gerenciamento, Recursos Hídricos, Comunidade.

Departamento Autônomo de Água e Esgotos - DAAE de Araraquara (SP). 


\section{REPRESENTAÇÕES SOCIAIS DO ACESSO À ÁGUAPOTÁVELE DAS PRÁTICAS DE USO: A DIMENSÃO RELIGIOSA DA VIDA COTIDIANA EM CABACEIRAS-PB}

Cavalcanti Filho, José Rocha*; Gallo, Zildo**

A cidade de Cabaceiras, localizada no semi-árido paraibano, é o município onde menos chove no país. Apresenta temperatura média de $30^{\circ} \mathrm{C} \mathrm{e} \mathrm{menos} \mathrm{de} 200 \mathrm{~mm} \mathrm{de}$ chuva durante $\mathrm{o}$ ano todo, com precipitações em apenas dois meses, alcançando períodos secos de até 10 meses. É uma região habitada por populações pobres e de extrema carência, cuja fonte de sustentabilidade se encontra na agricultura familiar. Os projetos sociais desenvolvidos têm o caráter de atender apenas às necessidades imediatas, socorrendo essas populações com o abastecimento de água através de carros-pipa, a distribuição de cestas básicas e o trabalho realizado pelas frentes de emergência. Aágua é elemento vital no desenvolvimento sustentável e a seca ou as enchentes constituem-se em um fato social agravado pelo comportamento humano. Sendo a região carente de chuvas, percebe-se nas minorias religiosas a acomodação para esse fator climático, levando-as a perceber a água como um dom de Deus. Para entender melhor esse simbolismo, a Teoria das Representações Sociais fundamenta a análise dessa condição específica de construção do conhecimento e de práticas sobre a água (acesso, uso e manejo) por essa população profundamente influenciada por sua formação religiosa.

Palavras-chave: Manejo da Água, Estudo Sociológico, Semi-Árido Nordestino, Cristianismo Popular.

*Aluno do Programa de Mestrado em Desenvolvimento Regional e Meio Ambiente do Centro Universitário de Araraquara - Uniara.

**Docente do Programa de Mestrado em Desenvolvimento Regional e Meio Ambiente do Centro Universitário de Araraquara - Uniara.

REVISTA UNIARA, $n .^{0} 21 / 22,2008 / 2009$
IMPACTOS AMBIENTAIS DOS RESÍDUOS DE CONSTRUÇÃO E DEMOLIÇÃO NO MUNICÍPIO DE ARARAQUARA/SP

FREITAS, Isabela Mauricio*; HERMANN, Hildebrando**

Os resíduos de construção e demolição têm se tornado um problema cada vez maior para o município de Araraquara/SP que, carente de áreas para o adequado descarte desses resíduos, acaba sofrendo com os impactos ambientais decorrentes da deposição irregular de entulhos em áreas que não são controladas ou fiscalizadas pelo poder municipal. Com o objetivo de caracterizar os principais impactos ambientais ocorridos em áreas utilizadas como depósito clandestino de entulhos, foram identificadas as áreas mais suscetíveis aos impactos ambientais. Os dados foram obtidos por meio de pesquisa de campo e aplicação de questionário "in loco" abordando os seguintes aspectos: tipos de impactos ocorridos nas áreas identificadas e existência de atenuantes impactantes. Os resultados relacionados aos impactos ambientais nas áreas identificadas indicaram que a maioria dessas áreas se encontra nas regiões periféricas da cidade, onde a população tem menor poder aquisitivo e acesso a programas de educação e conscientização ambiental. Em relação aos impactos foram constatados: degradação da paisagem urbana, assoreamentos, degradação de margens de Córregos (APPs), obstrução da via pública e proliferação de vetores. Em relação aos atenuantes impactantes foram constatados: deposição irregular de diversos tipos de resíduos, ocorrência de queimadas e grande quantidade de animais peçonhentos como o escorpião. A ocorrência de impactos ambientais nas áreas identificadas como depósitos clandestinos de entulhos ficou evidenciada pela falta de intensa fiscalização do poder público municipal e ações que visem à minimização de tais disposições irregulares que tantos impactos causam ao meio ambiente e a qualidade de vida da população.

Palavras-chave: Impactos Ambientais, Disposições Irregulares, Resíduos de Construção e Demolição, Destinação Final Correta.

*Aluna do Programa de Mestrado em Desenvolvimento Regional e Meio Ambiente do Centro Universitário de Araraquara - Uniara.

**Docente do Programa de Mestrado em Desenvolvimento Regional e Meio Ambiente do Centro Universitário de Araraquara - Uniara. 
PERFIL SOCIOECONÔMICO DE OLERICULTORES FAMILIARES DE ITABAIANA/SE

SOUZA, Danielle Thaís Barros de*; GOMES, Laura Jane*

A modernização da agricultura brasileira ocorreu a partir do conjuntode transformações estruturais e passou definitivamente a integrar a produção industrial, ou seja, o agronegócio. A produção rural passou a situar-se, economicamente, entre as indústrias produtoras de bens e insumos para a agricultura e as indústrias processadoras de serviços de base agrícola. A atividade agrícola, que era de subsistência e auto-suficiência, tornou-se uma unidade dependente do mercado e das indústrias de insumos e processamento. Este artigo analisa o perfil socioeconômico dos produtores de hortaliças na cidade de Itabaiana no estado de Sergipe. Foram utilizadas técnicas de levantamento e observação obtidas através de fontes primárias, sendo realizado um estudo de campo do tipo exploratório e descritivo realizado a partir de entrevista semi-estruturada com 28 proprietários de olericulturas da cidade de Itabaiana/SE, selecionados por serem fornecedores da Rede de Supermercados G Barbosa. A coleta dos dados ocorreu dos meses de maio a julho de 2007 e as variáveis pesquisadas foram tabuladas, distribuídas percentualmente e demonstradas por meio de gráficos e tabelas no programa Excel da Microsoft, sendo consideradas de forma descritiva. Os resultados evidenciam o predomínio do gênero masculino na atividade administrativa; o baixo nível de escolaridade; que os sistemas produtivos acompanhados em geral possuem um único proprietário. Nem toda a área das propriedades é utilizada para cultivo. Faltam recursos financeiros para investir na produçãoe compradores. Foi observado que é cultura na região ceder terras para criações de parentes e conhecidos. Na maioria dos sistemas produtivos apenas o proprietário vinha desenvolvendo atividades. A presença de membros da família nos sistemas de produção olerícolas estudados ainda é presente, confirmando o relevante papel socioeconômico que a agricultura familiar exerce sobre o agronegócio brasileiro. Épossível classificar os sistemas produtivos de olerícolas como agricultura familiar moderna. Recomenda-se a adoção de modelos de gestão para identificar as causas dos problemas e evitar medidas de caráter corretivas, possibilitando a definição de alternativas que sejam viáveis economicamente e que contribuam de forma efetiva para a melhoria da qualidade de vida.

Palavras-chave: Sistemas de Produção, Gestão,Administração Rural, Olericultura, Agricultura familiar.

*Universidade Federal de Sergipe.

REVISTA UNIARA, $n .^{0} 21 / 22,2008 / 2009$
ESTUDO DO SISTEMA DE GERAÇÃO DE ENERGIA UTILIZANDO BIOGÁS PROVENIENTE DE ATERRO SANITÁRIO: EXPERIÊNCIAS NO ATERRO BANDEIRANTES E DELTA

ALVES, C.B. *; FLORIAN, F*

Os aterros sanitários representam a maneira mais barata de manejar os resíduos sólidos urbanos, industriais e domésticos. Obiogás, um gás produzido pela conversão de biomassa sólida em gás, pode ser produzido por aterros sanitários, esterco bovino e suíno, bem como por estações de tratamento de efluentes (ETE) de esgoto doméstico e industrial. Este gás é um dos produtos da decomposição anaeróbica da matéria orgânica, que se dá por meio da ação de determinadas espécies de bactérias. Este trabalho visa identificar a importância de algumas experiências no processo de geração de energia elétrica aproveitando resíduos sólidos urbanos provenientes de aterros sanitários. Foi realizada uma pesquisa bibliográfica, a fim de compreender alguns conceitos e tecnologias utilizadas na conversão energética. Alguns resultados parciais demonstram que tecnologias em projetos de gaseificação de aterros estão sendo realizadas recentemente. Cabe destacar o Aterro Bandeirantes, considerado um dos maiores aterros do mundo, localizado no Município de Perus/SP, na redução da emissão equivalente a 8 milhões de toneladas de gás carbônico no período de 15 anos, contribuindo para mitigação do efeito estufa. O Aterro Delta, localizado no Município de Campinas-SP, revelou que o potencial gerado de energia elétrica em 2003, foi de aproximadamente três mega watt. Elevados teores de metano foram os principais responsáveis por essa quantidade gerada.

Palavras-chave: Aterro Sanitário, Resíduos Sólidos Urbanos, Biogás.

*Centro Universitário de Araraquara - Uniara.

Gestão Ambiental 


\section{LEVANTAMENTO FLORÍSTICO COM ESPÉCIES DA MATA CILIAR EM ÁREAS DE MINERAÇÃO DE ARGILA NA CIDADE DE SÃO ROQUE DO CANA ̃̃-ES}

\author{
FREITAS, Gerson*; ZACHARIAS, Luiz Carlos*; GALLO, Zildo**
}

Muitos trabalhos de pesquisa têm sido desenvolvidos no tocante à recuperação de áreas degradadas. Entretanto, cada área degradada possui especificidades quanto aos processos que a levaram ao seu atual estágio de degradação e, destes processos, muito dependem as estratégias ideais de intervenção para a restauração das funções ecológicas desempenhadas por determinada área. Assim, faz-se necessário que sejam testados modelos de recuperação ambiental diretamente relacionado à restauração florestal de áreas de empréstimo de material utilizado pela indústria de produção cerâmica (telhas, tijolos, pisos e outros), caso especificamente abordado neste trabalho, que teve como objetivo investigar impactos ambientais de mineração de argila e o processo de recuperação das áreas degradadas em São Roque do Canaã ES, com o estabelecimento de um Projeto Piloto de Revegetação, através de um amplo estudo do acervo bibliográfico e documental disponível com base no qual o referencial teórico foi fundamentado, e ainda um diagnóstico das áreas mineradas para observar o tamanho das mesmas, bem como suas possibilidades de uso como área piloto. Com os resultados obtidos - como balanço teórico acerca da temática abordada, levantamento fitossociológico, caracterização geográfica da área piloto e seu entorno, reuniões com representantes do poder público, da comunidade munícipe e empresários locais e realização dos cálculos de custo de implantação do projeto de reflorestamento, com aspectos adequados às áreas de extração de argila - foi desenvolvido um desenho de políticas públicas para o município, visando à recuperação de áreas florestais que envolvam atores individuais, coletivos, públicos e privados.

Palavras-chave: Mineração, Mata Ciliar, Recuperação, Degradação e Revegetação.

\footnotetext{
*Alunos do Programa de Mestrado em Desenvolvimento Regional e Meio Ambiente do Centro Universitário de Araraquara - Uniara.

**Docente do Programa de Mestrado em Desenvolvimento Regional e Meio Ambiente do Centro Universitário de Araraquara - Uniara.
}

ANÁLISE DE ARBORIZAÇÃO URBANA DO PROJETO CIDADE VERDE NO MUNICÍPIO DE JAÚ-SP

CAPPS, Ana Luiza de Almeida Prado*; QUEDA, Oriowaldo**; NAVARRO, Everton Chequeto***; FERREIRA, Homero Vicente****

O presente trabalho tem como objetivo analisar uma etapa da implantação do projeto "Cidade Verde", que tem como proposta arborizar a região central do município de Jaú (SP), além de verificar sua abrangência, resultados e averiguar a concepção que a população tem em relação à árvore. As ruas que o projeto abrange são: Treze de Maio, Marechal Bittencourt, Edgard Ferraz, Major Prado, Tenente Lopes, Quintino Bocaiúva, Sete de Setembro, Rangel Pestana, Humaitá, Paissandu, Visconde do Rio Branco, Riachuelo, Lourenço Prado, Campos Salles e Conde do Pinhal. No projeto, que visa à biodiversidade, as mudas deveriam ter altura mínima de 0,50 metro e sistema radicular consolidado no substrato. Nas ruas Edgard Ferraz e na Major Prado foram plantadas 133 mudas, todas elas de resedá. Foram substituídas 25 mudas, sendo que mais de $90 \%$ delas foram replantadas por causa de vandalismo. Já na Rua Treze de Maio foram plantadas 31 mudas, de várias espécies e quase $50 \%$ foram replantadas. Esse replantio ocorreu por causa da compactação do solo e do tamanho das mudas, (em média com 0,60 metro de altura), diferente das outras duas ruas, onde as mudas tinham 1,40 metro de altura. Verificou-se que o projeto não seguiu as próprias recomendações técnicas, já que em duas ruas $100 \%$ das mudas plantadas são de uma mesma espécie, não contemplando a biodiversidade que o projeto recomendava. Houve muito replantio por causa da compactação do solo e pelo fato de a equipe técnica não levar em conta a relação que os moradores têm estabelecido com as árvores. Assim, é importante que a população esteja envolvida com o projeto, dada a importância das árvores na arborização urbana, e que haja um melhor planejamento, com o objetivo de verificar a condição do solo, para que não se percam mudas.

Palavras-chave: Jaú, Arborização Urbana, Planejamento Arbóreo.

\footnotetext{
*Aluna do Programa de Mestrado em Desenvolvimento Regional e Meio Ambiente do Centro Universitário de Araraquara - Uniara.

**Docente do Programa de Mestrado em Desenvolvimento Regional e Meio Ambiente do Centro Universitário de Araraquara - Uniara.
}

***Secretaria de Meio Ambiente de Jaú/SP. 


\section{AVALIAÇÃO QUALITATIVADAARBORIZAÇÃO URBANA NO MUNICÍPIO DE JAÚ/SP}

NAVARRO, Everton Chequeto*; CAPPS, Ana Luiza de Almeida Prado*; FERREIRA, Homero Vicente*

A partir da premissa de que o planejamento prévio da arborização urbana é de essencial importância para alcançar êxito nas suas funções ecológicas, econômicas e sociais, o presente trabalho elencou os principais problemas relacionados à arborização dos passeios públicos no município de Jaú/SP, buscando dar diretrizes às tomadas de decisão na elaboração de futuros projetos de arborização urbana no município. Para o levantamento de informações foram utilizadas cem (100) solicitações de supressão de indivíduos arbóreos, cadastradas na seção de Protocolo da Prefeitura Municipal e escolhidas ao acaso. Para qualificar os indivíduos foi utilizada a planilha desenvolvida por Silva Filho (2002), que aborda os seguintes aspectos: localização, identificação da espécie, estado geral, aspectos fitossanitários, entre outros. Dos 116 indivíduos que totalizam 20 gêneros, 22 espécies e 14 famílias, $63,6 \%$ são espécies exóticas. Aespécie com maior prevalência éo Ligustrum lucidum, com 51,72\% das solicitações. OLigutrum lucidum é a espécie com maior participação nos prejuízos constatados em passeios públicos, tubulações das redes de água e esgoto e estruturas dos imóveis. Esses problemas podem ter origem na grande frequiência que a espécie apresenta no município, talvez maior que a recomendada, demonstrando um planejamento inadequado e puramente empírico. Assim, faz-se necessário a elaboração de um inventário quali-quantitativo da arborização urbana fornecendo informações sobre a necessidade de podas, tratamentos fitossanitários, remoções, plantios e freqüência das espécies no município.

Palavras-chave: Arborização Urbana, Planejamento Arbóreo, Jaú, Avaliação Qualitativa.

\section{POTENCIAL DO USO DE GEOPROCESSAMENTO NA CORRELAÇÃO DOS DADOS DE SAÚDE COM FATORES AMBIENTAIS. ESTUDO DOS CASOS DE DENGUE NO MUNICÍPIO DEARARAQUARA}

RIOS, Leonardo*; TEIXEIRA, Denílson*; TEODORO, Valter Luiz Iost*; COSTA, Daniel Jadyr Leite*; ORTIZ, Lucia Regina**

O reaparecimento de doenças, e em alguns casos a ocorrência de epidemias, mostra a magnitude do problema da saúde no Brasil. Dentre as doenças chamadas reincidentes, a dengue configura, no momento atual, a mais importante arbovirose que afeta o homem. O mapeamento para o entendimento da distribuição espaçotemporal, aliado à compreensão da difusão da doença e à eficácia das ações profiláticas e de controle, estão diretamente associadas à tomada de decisões eficientes no controle de epidemias e são os objetivos deste trabalho. Foi elaborado um sistema de informações geográficas para área urbana, adotando a quadra como unidade mínima de estudo. Os casos confirmados de dengue foram mapeados mensalmente, distinguindo casos de infecção ocorridos na cidade (casos autóctones) e de infecção ocorridos em outras cidades e manifestados em Araraquara (casos importados). Janeiro de 2007 apresentou 9 casos importados e nenhum caso autóctone. A partir de fevereiro de 2007, os casos autóctones foram maiores do que os importados ( 9 e 8 casos respectivamente) e em abril de 2007 ocorreu o maior número de casos autóctones (120 casos confirmados), sendo que o maior número de casos importados ocorreu em março de 2007 (17 casos confirmados). Essa distribuição temporal mostra a rápida contaminação do vetor e da população. $\mathrm{O}$ município viveu um aumento significativo de casos, que até abril de 2008 contabilizavam mais de 1100. A epidemia ocorreu em função da combinação de uma série de fatores, entre eles: as condições adequadas para proliferação do mosquito vetor Aedes aegypti, a falta de recursos e estrutura do setor público, além da ausência de práticas preventivas por parte da população.

Palavras-chave: Dengue, Sistema de Informações Geográficas, Araraquara. 
VARIAÇÃO NICTEMERAL DE PARÂMETROS BIOLÓGICOS NO RIBEIRÃO DAS CRUZES (ARARAQUARA-SP)

SANTOS, Vitor Rocha dos*; TEIXEIRA, Denílson**

O uso inadequado das águas, sua degradação e a distribuição desigual desse recurso podem comprometer a quantidade e qualidade necessária às gerações futuras, bem como gerar conflitos de interesses entre os segmentos industrial, urbano e agrícola. Torna-se, então, de grande importância a realização de estudos sobre a qualidade dos recursos hídricos, partindo da análise da variação temporal de parâmetros limnológicos. O objetivo do presente estudo é comparar a qualidade da água no ribeirão das Cruzes antes e depois do lançamento do efluente da ETE - Araraquara em um período de 24 horas. A determinação da concentração dos coliformes assume importância como parâmetro indicador da possibilidade da existência de microorganismos patogênicos. A coleta de dados, compreendendo um período diário, foi realizada com o intuito de observar as oscilações limnológicas de um corpo de água. Pode-se concluir que o parâmetro analisado apresenta uma variação significativa entre os pontos à montante e à jusante; isso se deve principalmente à influência da entrada do efluente da ETE - Araraquara e às horas que foram realizadas as coletas.

Palavras-chave: Variação Nictemeral, Bacia Hidrográfica, Qualidade de Água.

*Aluno do Programa de Mestrado em Desenvolvimento Regional e Meio Ambiente do Centro Universitário de Araraquara - Uniara.

**Docente do Programa de Mestrado em Desenvolvimento Regional e Meio Ambiente do Centro Universitário de Araraquara - Uniara.
MAPEAMENTO DO USO E OCUPAÇÃO DO SOLO E ANÁLISE DE UM PARÂMETRO INDICADOR DE QUALIDADE DA ÁGUA DA SUB-BACIA DO RIBEIRÃO DO OURO (ARARAQUARA-SP)

TEIXEIRA, Denílson*; RIOS, Leonardo*; COSTA, Daniel Jadyr Leite**; FULLER, Beatriz Buda***; SILVA, Lívia Nunes***; TEODORO, Valter Luiz Iost****

Diferentes instrumentos de planejamento e gestão ambiental vêm sendo propostos, tendo em vista a preservação da qualidade ambiental e as mitigações de impactos ambientais em bacias hidrográficas. Para a integração dessas ações é necessária a construção de um banco de dados sistematizado e atualizado, imprescindível para a organização efetiva do território e para o entendimento da dinâmica do desenvolvimento regional, acompanhada de um monitoramento de variáveis ambientais indicadoras da qualidade da água. Assim, este trabalho apresenta o mapeamento do uso e ocupação do solo, por meio de um Sistema de Informações Geográficas (SIG) e dados referentes à demanda bioquímica de oxigênio (DBO), para o ano de 2006, para a sub-bacia do Ribeirão do Ouro. O mapa de uso e ocupação do solo foi elaborado através de classificação digital supervisionada de imagens de satélite. As amostras de água foram

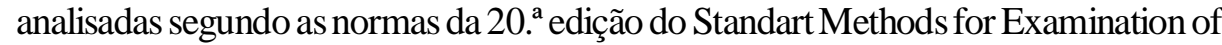
Water and Wastewater e foi utilizada como legislação padrão a resolução CONAMA 357/05. Os resultados demonstram que a sub-bacia está predominantemente ocupada por áreas agrícolas e pastos, seguidas de áreas urbanas, e que a água do ribeirão apresenta uma DBO acima do nível estipulado pela legislação nas estações de amostragem localizadas na área agrícola, observando-se nessa área o processo de autodepuração da matéria orgânica. Portanto, a utilização do SIG juntamente com a análise de componentes físicoquímicas, permite que o cenário estudado seja sistematicamente atualizado e analisado de forma integrada. Dessa forma, a proposta metodológica apresenta grande potencial para subsidiar as discussões em torno do processo de desenvolvimento regional, além de auxiliar a construção de políticas públicas.

Palavras-chave: Sub-bacia Hidrográfica, Uso e Ocupação do Solo, Qualidade de Água.

*Docentes e pesquisadores do Programa de Mestrado em Desenvolvimento Regional e Meio Ambiente da Uniara.

**Apoio Técnico do Programa de Mestrado em Desenvolvimento Regional e Meio Ambiente da Uniara ***A Alunas do Programa de Mestrado em Desenvolvimento Regional e Meio Ambiente da Uniara. ****Mestre em Desenvolvimento Regional e Meio Ambiente pelo Programa de Mestrado em Desenvolvimento Regional e Meio Ambiente do Centro Universitário de Araraquara - Uniara. 
PERFILDAESTRUTURAAMBIENTALDOS MUNICÍPIOS QUE COMPÕEMA UNIDADE DE GERENCIAMENTO DE RECURSOS HÍDRICOS TIETÊ-JACARÉ COMO SUBSÍDIO À GESTÃO SISTÊMICA, INTEGRADA E DESCENTRALIZADA DOS RECURSOS HÍDRICOS

TEIXEIRA, Denílson*; TEODORO, Valter Luiz Iost**; COSTA, Daniel Jadyr Leite***; FULLER, Beatriz Buda****; SILVA, Lívia Nunes****

As bacias hidrográficas são as unidades preferenciais para gestão integrada dos recursos hídricos, pois permitem uma abordagem sistêmica, ou seja, observar como as relações ecológicas, econômicas, sociais e culturais intervêm nos usos múltiplos dos recursos hídricos. Adivisão das bacias hidrográficas em Unidades de Gerenciamento de Recursos Hídricos (UGRHI) foi uma ação importante para gestão integrada e descentralizada dos recursos hídricos. Diante disso a presente pesquisa teve como objetivo avaliar o perfil da estrutura ambiental dos municípios da UGRHI Tietê-Jacaré. Os indicadores utilizados para o desenvolvimento do trabalho foram selecionados junto ao Instituto Brasileiro de Geografia e Estatística (IBGE), referentes ao perfil ambiental dos municípios brasileiros do ano de 2002, e à Fundação Estadual de Análise de Dados (SEADE), relativos a 2003. Os resultados revelam que 64,7\% não apresentam Secretarias nem Conselhos Municipais de Meio Ambiente, enquanto apenas 11,7\% dos municípios apresentamambas as estruturas. Dos 34 municípios, 17,6\% apresentam Secretarias de Meio Ambiente e 29,4\% apenas o Conselho Municipal de Meio Ambiente. Em relação às legislações específicas sobre proteção e controle ambiental, somente 17,6\% dos municípios as apresentam, enquanto $82,4 \%$ não. O mesmo ocorre em relação aos recursos específicos para o meio ambiente, ou seja, a maioria - 70,6\% - não recebeu recursos, enquanto $29,4 \%$ receberam. Dessa forma, torna-se difícil a gestão sistêmica, descentralizada e integrada da UGRHI, pois os municípios não possuem infra-estrutura adequada para gerir as questões ambientais como manutenção da qualidade e quantidade dos recursos hídricos, imprescindíveis para o desenvolvimento local e regional.

Palavras-chave: Gestão Integrada de Recursos Hídricos, Unidades de Gerenciamento de Recursos Hídricos, Desenvolvimento Local e Regional.

*Docentes e pesquisadores do Programa de Mestrado em Desenvolvimento Regional e Meio Ambiente da Uniara.

**Mestre em Desenvolvimento Regional e Meio Ambiente pelo Programa de Mestrado em Desenvolvimento Regional e Meio Ambiente do Centro Universitário de Araraquara - Uniara.

***Apoio Técnico do Programa de Mestrado em Desenvolvimento Regional e Meio Ambiente da Uniara. ****Alunas do Programa de Mestrado em Desenvolvimento Regional e Meio Ambiente da Uniara.
MANEJO SUSTENTÁVEL DAS ÁGUAS PLUVIAIS NO MUNICÍPIO DEARARAQUARA

Osório, A.L.*

O crescimento populacional e conseqüente expansão da área urbana caracterizaram um agravamento relevante da ocupação e gestão dos centros urbanos, criando assim notáveis alterações no ciclo hidrológico natural e promovendo situações favoráveis para o desequilíbrio e insustentabilidade do desenvolvimento. O objetivo desta proposta é estabelecer um planejamento urbano integrado e participativo, com foco na efetivação e integração do manejo sustentável das águas pluviais com todos os atuais setores ligados direta ou indiretamente ao saneamento ambiental. Segundo o Instituto de Pesquisas Hidráulicas da Universidade Federal do Rio Grande do Sul, através do autor André Luiz Lopez da Silveira (2002), a drenagem urbana moderna deve ter os seguintes conceitos: não transferir impactos a jusante; não ampliar cheias naturais; propor medidas de controle para o conjunto da bacia; legislação e planos de drenagem para controle e orientação; constante atualização de planejamento por estudo de horizontes de expansão; controle permanente do uso do solo e áreas de risco; competência técnico-administrativa dos órgãos públicos gestores; educação ambiental qualificada para o poder público, população e meio técnico. O que há é a proposição de mudança de paradigma da gestão da drenagem urbana de um enfoque sanitáriohigienista, para um enfoque ambiental. As experiências iniciais do Departamento Autônomo de Água e Esgoto - DAAE no manejo sustentável das águas pluviais contemplam diretrizes e solicitações a novos empreendimentos de grande porte (loteamentos, condomínios horizontais e verticais, indústrias e comércios), abrangendo aspectos de controle quantitativo e qualitativo das águas pluviais. No aspecto quantitativo o ideal é fazer com que o ciclo hidrológico no meio urbano tenha volumes de água nos diversos compartimentos (escoamento superficial, infiltração no solo, evapotranspiração) em níveis análogos à situação de pré-urbanização. No aspecto qualitativo deve-se buscar: evitar o carreamento de poluentes e contaminação para dentro do solo e aqüíferos junto com a infiltração; acumulação de poluentes, esgotos, sedimentos e lixo nos locais destinados à acumulação de escoamento pluvial.

Palavras-chave: Drenagem Urbana; Manejo Sustentável, Água Pluvial.

\begin{abstract}
*Engenheiro civil, mestre em Engenharia Urbana pela Universidade Federal de São Carlos - UFSCar coordenador de Fiscalização Ambiental da Coordenadoria Executiva de Meio Ambiente e Engenheiro Civil do Departamento Autônomo de Água e Esgoto - DAAE.
\end{abstract}


FERREIRA, Natália Noronha*; RIBEIRO, Maria Lúcia**; SANTOS, Ademir***; OLIVEIRA, Luciana Camargo***; BOTERO, Wander***

Substâncias húmicas (SH) são agregados moleculares heterogêneos, possuem estrutura indefinida e constituem a principal fração da matéria orgânica natural. Devido ao elevado número de grupos funcionais presentes em sua estrutura, podem atuar como agentes complexantes, influenciando diretamente no transporte, acúmulo, biodisponibilidade e toxicidade de diferentes substâncias. Dentre os contaminantes ambientais se destacam os metais, pela sua ampla aplicabilidade em diferentes setores e por não sofrerem degradação química ou biológica. Contaminações agudas e crônicas por metais potencialmente tóxicos em seres humanos têm sido relatadas na literatura. $\mathrm{O}$ tratamento sugerido consiste no emprego de agentes complexantes como o etilenodiaminotetraácetico (EDTA). Entretanto, devido à sua baixa seletividade, $\mathrm{o}$ EDTA complexa diferentes espécies no organismo humano, inclusive nutrientes, sendo necessária a reposição pela ingestão de sais minerais. Os ?-aminoácidos têm sido utilizados com o mesmo propósito, porém são muito caros e apenas aplicados na forma injetável. As SH apresentam a possibilidade de cumprir a dupla função de complexar os metais potencialmente tóxicos e liberar nutrientes essenciais. Nesse sentido, SH foram enriquecidas com cálcio e magnésio e realizou-se um estudo de troca entre estes macronutrientes e níquel em concentrações crescentes $(0,25-20$ $\mathrm{mg} / \mathrm{L}$ ). As soluções dos trocadores foram analisadas por espectrometria de emissão atômica por plasma de argônio induzido avaliando-se as concentrações dos macronutrientes e do metal tóxico. Os resultados mostraram maior afinidade das SH pelo níquel do que pelos macronutrientes, possibilitando a complexação do níquel em sua estrutura e, conseqüentemente, a liberação de cálcio e magnésio, confirmando a viabilidade da utilização de $\mathrm{SH}$ como agentes terapêuticos.

Palavras-chave: Substâncias Húmicas, Níquel, Metais Potencialmente Tóxicos, Capacidade de Complexação.

*Bolsista de apoio Funadesp - Centro Universitário de Araraquara - Uniara.

**Docente do Programa de Mestrado em Desenvolvimento Regional e Meio Ambiente do Centro Universitário de Araraquara - Uniara.

***Pesquisador do Instituto de Química da Unesp de Araraquara.

\section{Agricultura e} Desenvolvimento 
PESTICIDAS NA CULTURA DE LARANJA NO MUNICÍPIO DE ITÁPOLIS-SP

BOCCHI, Lílian Maria Andreotti*; OLIVEIRA, Luciana Camargo*; RIBEIRO, Maria Lúcia*

Este trabalho teve como objetivo avaliar o potencial de contaminação dos recursos hídricos por pesticidas usados nas propriedades citrícolas de Itápolis-SP. Este município, responsável por 4,0\% da produção nacional de laranja, está localizado na Bacia Hidrográfica Tietê-Batalha, dentro da região do Aquífero Guarani, e a água subterrânea é a principal fonte de abastecimento de sua população. Adeterminação do potencial de contaminação das águas subterrâneas e superficiais por pesticidas foi realizada por estimativas indiretas, pela aplicação de modelos matemáticos: Critérios da EPA, Índice de GUS, Índice LIX e Critérios de Goss. A utilização de pesticidas é realizada de forma multiquímica em $100 \%$ das propriedades, contemplando as seguintes classes: inseticidas (51,6\%), acaricidas (29,0\%), fungicidas $(12,9 \%)$ e herbicidas $(2,0 \%)$. Dos 12 pesticidas, selecionados para avaliação do potencial de contaminação dos recursos hídricos, em razão de serem os mais freqüentemente utilizados nas propriedades ( 1 herbicida, 5 inseticidas, 1 fungicida e 5 acaricidas), $75 \%$ possuem potencial de contaminação de águas superficiais, $41,7 \%$ de águas subterrâneas e $16,7 \%$ para ambas. Dentre os pesticidas com potencial de contaminação de águas subterrâneas e ou/ superficiais, 50\% pertencem à classe toxicológica III (medianamente tóxicos para o ser humano). Em relação ao perigo que representam para o meio ambiente, $50 \%$ dos pesticidas são da classe ambiental III (perigosos para o ambiente). O conjunto dos métodos usados indica quais princípios ativos, efetivamente usados na citricultura do município de Itápolis, devem ser selecionados e priorizados em programas de monitoramento ambiental fornecendo subsídios para ações de políticas públicas.

Palavras-chave: Citricultura, Pesticidas, Recursos Hídricos, Contaminação.

*Centro Universitário de Araraquara - Uniara.
O PAPEL DAASSOCIAÇÃO DO BAIRRO DOS GARCIAS NA RECUPERAÇÃO DA BACIA HIDROGRÁFICA DO RIO MOGIGUAÇU BOM REPOUSO-MG

NISHIKAWA, Lucia Lopes Nishikawa.*; FERREIRA. D. Ap. de O.*

AAssociação do Bairro dos Garcias, no Município de Bom Repouso-MG, é uma entidade que surge como uma alternativa à forma de produção convencional que tem por base o uso de agroquímicos. As ações dos agricultores associados apresentam duas concepções importantes: a diversificação da atividade produtiva e a substituição da prática agrícola convencional para o sistema orgânico. Diante dessa observação optamos por avaliar o desempenho da mesma no que compete aos seus aspectos socioculturais, para uma compreensão de como a ação desses atores sociais interferem da realidade do entorno da Bacia hidrográfica do Rio Mogi-Guaçu. Por meio de entrevistas semi-diretivas e a aplicação de questionários entre os agricultores que desenvolvem a atividade da agricultura orgânica no Bairro dos Garcias, em Bom Repouso-MG foi possível conhecer e verificar o desempenho produtivo dessa associação. Aentidade apresenta resultados econômicos positivos, pois os agricultores associados têm obtido uma renda extra por meio da venda dos produtos ao CONAB (Companhia Nacional de Abastecimento): programa do governo Federal que compra os produtos dos agricultores e repassa para o CONSEA(Conselho Nacional de Segurança Alimentar e Nutricional) que os envia às escolas da cidade. Quanto ao aspecto educacional a atuação da associação tem mostrado bons resultados, na medida em que vem sensibilizando os estudantes a se tornar agentes ambientais: aprendendo os princípios da agricultura orgânica, as práticas de conservação de solos e dos recursos hídricos e a importância da cobertura vegetal, eles se tornam multiplicadores da concepção de uma produção voltada para o meio ambiente, inclusive sugerindo aos pais, produtores convencionais, a adoção ao sistema orgânico. Percebese, então, a importância dessa associação, que se apresentar como agente de uma estratégia social, à medida que rompe com o modelo produtivo e coloca em discussão suas implicações sociais, econômicas, políticas e ecológicas, junto à comunidade e às unidades de ensino. E também evidencia a existência de um nicho de mercado que busca produtos que preservem as condições ambientais e sociais, permitindo assim a inserção de um maior número de agricultores familiares por meio da formação de novas associações.

Palavras-chave: Bacia Hidrográfica, Associação do Bairro, Atores Sociais.

*Doutorandas no Programa de Pós-Graduação em Sociologia, Faculdade de Ciências e Letras, Unesp, Araraquara/SP.

Agricultura e Desenvolvimento 


\section{TRAVESSIAS DE FAMÍLIAS CAMPONESAS MIGRANTES}

$$
\text { ARONI, R.*; SILVA, M.A.M.** }
$$

O presente resumo propõe apresentar dados preliminares da pesquisa em curso sobre a análise da possível recomposição camponesa no território paulista. Buscase analisar os efeitos do processo migratório e do trabalho assalariado, impulsionados pela expansão do setor produtor de açúcar e álcool no noroeste paulista - municípios de Sales, Novo Horizonte e Mendonça/SP. Busca-se também compreender como a dinâmica do fenômeno da migração de retorno se articula ao processo de expropriação e estratégias de reprodução camponesa, além de investigar as formas de reorganizações dos grupos familiares, na estratégia do assalariamento para ganhos imediatos e na apropriação do território migratório de destino por família originárias do Nordeste brasileiro. Para a compreensão da migração temporária de famílias camponesas do sertão paraibano para o interior do Estado de São Paulo, procedese com aplicação aleatória de questionários, etnografias dos espaços de alojamento, história oral, por meio da coleta de depoimentos, registros fotográficos e fontes escritas, basicamente a análise dos prontuários de atendimento da Secretaria de Assistência Social de Novo Horizonte-SP. A análise dos 26 questionários aplicados, nos municípios citados, apontou para idade média de 27 anos dos casais de migrantes. Quanto ao pertencimento da origem geográfica, são 15 casais paraibanos, 9 pernambucanos, e 2 baianos. A média de escolaridade dos homens é até a quarta série e oitava série (ensino fundamental) para mulheres. A média de filhos foi de 1,3. Foi constatado que $46 \%$ das mulheres trabalham fora, e o mesmo percentual recebe bolsa-família, auxílio gás ou renda cidadã. Aproximadamente $80 \%$ dos pais dos casais apresentam origem camponesa. Algumas hipóteses foram confirmadas, contudo merecem ser mais bem investigadas, como a questão do emponderamento das mulheres frente ao domínio patriarcal, o conflito no rearranjo familiare a predominância da origem camponesas das famílias.

Palavras-chave: Família e Gênero, Territórios Migratórios, Migração e Gênero, Família.

\footnotetext{
*Programa de Mestrado em Sociologia, linha de pesquisa Urbanização, Ruralidades, Desenvolvimento Sustentável e Ambiental da Universidade Federal de São Carlos-SP. Bolsista da Fapesp.

**Docente do Programa de Pós-Graduação em Sociologia - Urbanização, Ruralidades, Desenvolvimento Sustentável e Ambiental da Universidade Federal de São Carlos-SP
}

A PRODUÇÃO DOAUTOCONSUMO ALIMENTAR NUM ASSENTAMENTO RURAL FRENTE ÀS POLÍTICAS PÚBLICAS

DUVAL, Henrique Carmona*

Esta comunicaçãoé parte da pesquisa de mestrado SegurançaAlimentar no Âmbito de um Assentamento Rural: desafios da produção de autoconsumo, desenvolvida no PPG em Agroecologia e Desenvolvimento Rural - CCA/UFSCar. A perspectiva de que a segurança alimentar pode ser obtida pelo reordenamento agrário e pelo acesso à terra para famílias que almejam uma vida num assentamento rural, através das produções que elas fazem com o objetivo de autoconsumo familiar, é observada no assentamento rural Monte Alegre, na região de Araraquara. O principal objetivo do estudo é descrever e analisar as origens e trajetórias de famílias até o assentamento e como se dá a produção de alimentos no interior dos lotes. Pretendemos dimensionar como era o acesso a alimentos por parte desta população antes e depois do assentamento. Concomitantemente, se esta produção agrícola se dá a partir de conhecimentos tradicionais ou convencionais, para então enquadrá-la em princípios agroecológicos ou não. $\mathrm{O}$ marco teórico desta discussão imbrica os temas: assentamentos rurais, produção de autoconsumo, segurança alimentar, agricultura sustentávele impactos das mudanças climáticas na agricultura. As técnicas da pesquisa são diários de campo, roteiro para depoimentos orais, análise documental, fotodocumentação e mapas mentais. Como resultados preliminares, verificamos que a prática de autoconsumo é bem freqüente entre os lotes do assentamento, em muitos casos correspondendo à maior parte do que uma família consome. Os alimentos plantados para autoconsumo alimentar exercem um importante papel na sociabilidade e na reprodução social no interior dos assentamentos, respectivamente, através das trocas e doações de alimentos entre famílias e porque há uma transmissão de conhecimentos da cultura tradicional dos mais velhos para os mais novos. Quanto mais alimento plantado no assentamento, maiores as chances de que toda a demanda alimentar do mesmo seja suprida internamente e, a depender da eficácia das políticas públicas, tal produção pode também suprir, em boa medida, a demanda municipal.

Palavras-chave: Assentamentos Rurais, Agricultura Familiar, Autoconsumo, Tradição.

*Programa de Pós-Graduação em Agroecologia e Desenvolvimento Rural - UFSCar.

Agricultura e Desenvolvimento 
CONFLITOS E NEGOCIAÇÕES EM PROJETOS DE

DESENVOLVIMENTO RURAL SUSTENTÁVEL: O CASO DO ASSENTAMENTO MÁRIO LAGO - RIBEIRÃO PRETO-SP

GONÇALVES, José Cláudio*; SCOPINHO, Rosemeire Aparecida**

Desde meados dos anos 1990, pesquisadores, governos e movimentos sociais têm se debruçado sobre as novas configurações do meio rural brasileiro, em especial aquelas decorrentes da implantação de projetos baseados na sustentabilidade agroambiental. Estudos recentes mostram que esse processo resulta de uma nova visão sobre o rural, isto é, uma nova concepção sobre as possibilidades de desenvolvimento agropecuário nos diferentes agroecossistemas do país. No contexto deste debate, os assentamentos da reforma agrária vêm sendo considerados espaços importantes para a implantação de projetos de desenvolvimento agropecuários pautados nos princípios da agroecologia. Isto posto, o objetivo desse trabalho é desenvolver uma análise acerca da convergência entre as questões agrária e ambiental na região nordeste do Estado de São Paulo. Nesse sentido, nos interessa compreender o processo de organização de um assentamento rural que tem a agroecologia como diretriz fundamental. O estudo de caso vem sendo desenvolvido no Assentamento Mário Lago, localizado no município de Ribeirão Preto. Esse assentamento foi implantado pelo Incra no modelo PDS (Projeto de Desenvolvimento Sustentável). O procedimento analítico dessa pesquisa se baseia na técnica da triangulação de informações obtidas a partir de diferentes fontes: entrevistas, observações e análise de documentos. Os materiais coletados e analisados até o presente momento indicam que a implantação desse modelo de assentamento, nessa região do Estado, parece não ser suficiente para uma transformação substantiva, seja das condições de degradação do ambiente, seja das condições materiais de vida dos agricultores e suas famílias.

Palavras-chave: Desenvolvimento Rural, Agroecologia, Reforma Agrária, Assentamentos Rurais, MST

*Universidade Federal de São Carlos - Programa de Pós-Graduação em Sociologia-Ppgs.
O AGRONEGÓCIO DA SEDA NO MUNICÍPIO DE GÁLIA-SPE O DESENVOLVIMENTO REGIONAL

PEREIRA, Marcos Alexandre Aparecido*; CONTADOR, Osvaldo Júnior*; MASSAN, Tiago*

Sericicultura é a criação da lagarta do bicho-da-seda (Bombyx mori L,) visando à produção de casulos do qual se extrai o fio de seda. Essa lagarta se alimenta somente de folhas de amoreira (Morus sp). Trata-se de uma atividade muito antiga e, segundo consta da história, teve início na China por volta de 4500 anos atrás. O Brasil é o $3 .^{\circ}$ maior produtor mundial de fios de seda. São Paulo é o $2 .^{\circ}$ maior estado brasileiro na produção nacional. Em Gália-SP existe a indústria Beraldin Sedas, que é a única no Continente Americano a deter o processo completo da seda. Com o objetivo de identificar a sericicultura como opção para a agricultura familiar e sua influência na geração de emprego e renda, elaborou-se um estudo de caso no município de Gália-SP, onde se obtiveram dados de caracterização econômica do município através de órgãos públicos e de produção dos sericicultores. Os resultados pertinentes à geração de emprego e renda mostraram-se desfavoráveis, porém a sericicultura no sistema de agricultura familiar contribui para o desenvolvimento do município e tem um alto cunho social, pois fixa o homem no campo. Embora esta atividade esteja diretamente relacionada com a sustentabilidade, responsabilidade sociale respeito ao meio ambiente, não é fonte de riqueza. Mesmo projetando o município de Gália-SP no cenário nacional, não houve evidências de cooperação entre a indústria têxtil, os produtores e os órgãos de pesquisa.

Palavras-chave: Sericicultura, Desenvolvimento Regional, Emprego.
*Faculdades Integradas de Jaú. 


\section{A GESTÃO AMBIENTAL NAS EMPRESAS DE INSUMOS AGRÍCOLAS EMSORRISO-MT}

COSTAJÚNIOR, Antonio Gil*

Sorriso, no estado do Mato Grosso, é o maior produtor mundial de soja e, consequientemente, um dos maiores consumidores de defensivos agrícolas. O trabalho teve como propósito levantar junto às empresas de insumos agrícolas da cidade o que estas têm feito em relação à questão ambiental. $O$ trabalho utilizou-se de pesquisa bibliográfica para a fundamentação teórica e um levantamento, por meio de questionário, aplicado nas empresas de Sorriso associadas à Comissão Estadual de Agricultores e Revendedores de Produtos Agropecuários do Mato Grosso. Em um questionamento direto sobre a existência de projetos em Gestão Ambiental, apenas $21 \%$ afirmaram ter algum tipo de projeto. Já quando questionados sobre reeducação ambiental para funcionários e clientes, $74 \%$ afirmaram ter este tipo de programa. Também se questionou sobre a utilização de algum meio para preservação ambiental, sendo que $79 \%$ responderam que ajudam de alguma forma, com a reutilização de papéis, redução de água e energia e outros. Mesmo com um resultado preocupante de que apenas $21 \%$ das empresas têm projetos em Gestão Ambiental, identificouse que outras empresas realizam ações, mas desconhecem que essas atividades fazem parte de um contexto da Gestão Ambiental. Entretanto, no geral, ainda há muito a ser feito, já que a maioria das empresas vê a implantação de qualquer atividade como custo e não querem "gastar", no momento, com Gestão Ambiental. Como as empresas de insumos agrícolas são fornecedoras de produtos que, se utilizados de forma indiscriminada, podem acarretar prejuízos ao meio ambiente, é de suma importância que estas estejam engajadas no desenvolvimento sustentável e de fato realizem projetos na área.

Palavras-chave: Gestão Ambiental, Insumos Agrícolas, Desenvolvimento Sustentável.

*Faculdade de Sorriso - FAIS/MT.

\section{ASSENTAMENTO MÁRIO LAGO: UMA EXPERIÊNCIA DE OCUPAÇÃO, ORGANIZAÇÃ̃ E PRODUÇÃO NO CENTRO DA INDÚSTRIAAGROCANAVIEIRA DO INTERIOR DO ESTADO DE SÃO PAULO}

BORELLIFILHO, Dorival*; FERRANTE, Vera Lúcia Silveira Botta**

O presente estudo de caso propõe-se a analisar o processo de ocupação que concedeu origem ao projeto de assentamento federal Mário Lago de Ribeirão PretoSP, bem como suas formas de organização interna e seu modelo agroecológico de produção. Para a coleta de dados junto às famílias assentadas, serão utilizadas, como ferramentas de pesquisa, técnicas qualitativas, além de dados quantitativos colhidos junto às instituições estatais (Incra e Itesp) responsáveis direta ou indiretamente pela administração do assentamento. Como técnicas qualitativas de pesquisa, serão empregadas a observação participativa e entrevistas semi-estruturadas com as lideranças do assentamento e com as famílias assentadas. Este assentamento se originou a partir de uma ocupação de terras liderada pelo MST no ano de 2003. Atualmente, é constituído por 350 famílias, subdivididas em 21 núcleos de moradia, que comportam de 15 a 25 famílias. Para cada núcleo, existe um coordenador e uma coordenadora geral, cujas responsabilidades são as orientações e a organização de cada núcleo. Simultaneamente a essa organização, existem coordenadores, de ambos os gêneros, que são responsáveis pelos seguintes setores: segurança, saúde, educação, ciranda infantil, esporte, cultura e lazer, jovens e produção. A ausência de políticas públicas no assentamento, nas áreas de saneamento básico, saúde, educação, coleta de lixo e transporte público vem gerando permanentes conflitos entre as famílias assentadas e o poder público local. O principal objetivo dos coordenadores do MST é recuperar esta área devastada pela ação predatória do agronegócio, utilizando-a para a agricultura orgânica, pretendendo construir um cinturão verde, que garanta o fornecimento de produtos orgânicos para a região.

Palavras-chave: Assentamento Mário Lago, Ocupação, Organização e Produção Agroecológica.

*Aluno do Programa de Mestrado em Desenvolvimento Regional e Meio Ambiente do Centro Universitário de Araraquara - Uniara.

* Docente e Coordenadora do Programa de Mestrado em Desenvolvimento Regional e Meio Ambiente do Centro Universitário de Araraquara - Uniara. 


\section{AGRICULTURA E CLASSE TRABALHADORA NO BRASIL}

SOUZA, Regina Maria*; SILVEIRA, Ubaldo**

O trabalho tem como objetivos analisar as modificações que ocorreram no processo de inserção da classe trabalhadora no meio rural brasileiro a partir da emergência dos complexos agroindustriais, bem como a dinâmica atual do referido processo. Para a realização da primeira fase da pesquisa trabalho foi utilizado método bibliográfico, que resultou em conclusões preliminares para a temática. É possível afirmar que existe estreita relação entre as modificações ocorridas no mundo do trabalho no meio rural e urbano no Brasil da segunda do século passado até os dias atuais, bem como ocorre a emergência de um novo padrão agrícola orientado para a introdução dos complexos agroindustriais, o que acabou por acentuar as desigualdades internas e garantir a hegemonia dos grandes produtores, em detrimento dos pequenos e médios produtores e dos projetos de reforma agrária. No Brasil, o acesso às terras livres pelas massas de migrantes e libertos foi restringido e, em consequiência, as populações rurais ou não tiveram acesso à terra ou ficaram prisioneiras da insegurança da posse da terra, transformando-se em força de trabalho de baixo custo, dependente de uma classe de latifundiários preocupados em garantir a expansão de suas atividades ao menor custo possível. Todas essas condições postas levaram à forte concentração da renda no campo, que somada à modalidade de inserção do país na divisão internacional do trabalho acabaram por limitar a expansão do setor urbano-industrial e a intensificar os desequilíbrios distributivos observados no processo de urbanização no Brasil.

Palavras-chave: Agricultura, Trabalho, Industrialização, Renda.
SUSTENTABILIDADE DAAGRICULTURA FAMILIAR PAULISTA EM ASSENTAMENTOS RURAIS DO ESTADO DE SÃO PAULO

LOPES, Paulo Rogério*; GAVIOLI, Felipe*; DE GASPARI, Luciane*; COSTA, Manoel Baltasar Baptista da*; BINOTTI, Túlio Caio**

O presente trabalho está voltado ao segmento da agricultura familiar, buscando contribuir com aportes metodológicos, informação e capacitação do segmento, em distintos campos afins a métodos de produção sustentável, sustentabilidade essa assumida em suas dimensões ecológico-produtivas, econômico-financeira, energética e sociocultural. A pesquisa desenvolve ações afins à agricultura sustentável e à agroecologia, com o intuito de gerar tecnologias alternativas de baixo custo, menos impactantes ao meio e adaptadas às necessidades dos agricultores assentados de três assentamentos rurais do Estado de São Paulo: Horto Loreto, situado no município de Araras; Santos Dias da Silva, localizado em Ribeirão Preto; e Monte Alegre, em Araraquara, Motuca e Matão. Tal pesquisa foi embasada em metodologias participativas, de acordo com PETERSEN (2005). Oenfoque participativo e coletivo das intervenções propiciará a formação de grupos de agricultores que, ao se associarem localmente em torno de projetos afins à agricultura ecológica, inovam nas práticas de manejo dos agroecossistemas, no convívio social e na expressão política, abrindo novas perspectivas econômicas e socioculturais de inserção no mundo rural. As metodologias de construção coletiva do conhecimento agroecológico variam conforme as distintas realidades, e estas devem ser flexíveis e adaptáveis, à medida que se conhecem melhor os anseios, expectativas e desejos do público com o qual se trabalha.

Palavras-chave: Agricultura Familiar, Assentamentos Rurais, Sustentabilidade e Desenvolvimento.
*Programa de Pós-Graduação em Agroecologia e Desenvolvimento Rural - PPGADR/UFSCar - Campus de Ciências Agrárias de Araras-SP.

**ESALQ/USP - Piracicaba-SP. 


\section{A TERRA INDÍGENA VANUÍRE, ARCO-ÍRIS-SP: IMPLICAÇÕES CULTURAIS E AMBIENTAIS NA CARACTERIZAÇÃO SOCIOAMBIENTAL}

RODRIGUES, Robson A.*; NISHIKAWA, Dulcelaine Lucia Lopes**

Evidenciar a necessidade de projetos específicos para as comunidades indígenas e que auxiliem na manutenção da sua alteridade e possibilidade de sua auto-sustentabilidade, subsidiados por pesquisas que permitam uma compreensão da realidade sociocultural e histórica dos povos indígenas, a partir de um novo paradigma de respeito à interculturalidade, ao multilingüismo e à etnicidade. Por meio de informações levantadas a partir do diagnóstico socioambiental foi possível levantar o quadro atual da aldeia indígena Índia Vanuíre sobre múltiplos aspectos. Para atingir os objetivos da pesquisa foram utilizados vários métodos: a aplicação de questionários, buscando a cobertura de todos os aspectos referentes ao uso e ocupação daárea, estudos etnográficos e pesquisa participante. O levantamento socioeconômico desenvolvido na área permitiu evidenciar que é possível apoiar projetos que vinculem a percepção social, ambiental e cultural das áreas de aldeias indígenas, buscando a compreensão desses espaços como um todo. No diagnóstico socioeconômico desenvolvido no âmbito da pesquisa foi realizada uma avaliação das áreas dereserva e mata ciliar no ambiente da aldeia indígena Índia Vanuíre, e os dados do laudo técnico evidenciaram que a área tanto do entorno quanto na aldeia indígena está em processo de degradação, devido às práticas agrícolas adotadas. É possível observar que as pesquisas desenvolvidas se baseiam na concepção de políticas meramente integracionistas, quando são necessários trabalhos com base na valorização da cultura indígena. Para tanto, é preciso novos alicerces, novos olhares, novos pensares, rompimento, de fato, com o modelo extensionista vigente, caso contrário, tudo continuará no mesmo lugar. Esse modelo de atuação não responde às necessidades das comunidades e só amplia o processo de degradação dos seus territórios, tanto culturais quanto ambientais. Os resultados evidenciaram a necessidade de projetos específicos para essas comunidades, que auxiliem na manutenção de seu modo de ser e que possibilite a sua auto-sustentabilidade. Para tanto, a ampliação dos seus territórios passa ser de grande importância para atingir esses objetivos.

Palavras-chave: Aldeia Indígena, Alteridade, Sustentabilidade.

*Professor e pesquisador associado do Ceimam/Unesp. Capes.

**Doutoranda no Programa de Pós-Graduação em Sociologia, Faculdade de Ciências e Letras da Unesp. Araraquara-SP.
RECUPERAÇÃO DE RECURSOS NATURAIS EM ASSENTAMENTOS E O CONCEITO DE PATRIMONIALIDADE AMBIENTAL. BREVE REVISÃO BIBLIOGRÁFICA

SILVA, Claudionor Renato*; TEIXEIRA, Denilson**; FERRANTE, Vera Lucia Silveira Botta**

Recuperação de recursos naturais em assentamentos tem sido realizada por órgãos administradores e de apoio técnico, como o Itesp, pautados nos princípios do desenvolvimento sustentável, em sua dimensão mais ampla. Nesse sentido o conceito de patrimonialidade ambiental vem sendo amplamente discutido e ampliado nos estudos sobre gestão de recursos naturais apontando o acesso livre aos recursos, aliado a uma ação reguladora desses recursos e sobrevivência dos envolvidos. Essa temática vem sendo amplamente discutida no projeto "Assentamentos x Desenvolvimentos (bloqueios, tensões e perspectivas) financiado pelo CNPq. O objetivo do presente trabalho é mapear as ações e programas de Recuperação Ambiental promovidos pelos órgãos governamentais responsáveis pela implantação de projetos de assentamento em parceria com os atores envolvidos. Num segundo momento, identificar a atualidade do conceito de patrimonialidade ambiental presente nas falas dos assentados, no amor e apego à terra, bem como a preocupação e comprometimento atual dos mesmos com a temática ambiental. A metodologia empregada é a pesquisa bibliográfica para as ações e práticas de recuperação ambiental de recursos naturais já desenvolvidas ou em andamento como também para as falas dos assentados. Os resultados apontam ações muito diretivas para a recuperação de recursos naturais em assentamentos através de ações em participação com a comunidade em Reservas Legais, Áreas de Proteção Permanente, recuperação de solos e, mais recentemente, projetos de Recuperação de Áreas Degradadas (RAD). Esta breve revisão bibliográfica aponta para a relevância do conceito para práticas de recuperação ambiental visando ao desenvolvimento das comunidades assentadas, bem como para apontamentos sobre a condição que deixaremos nosso meio ambiente e seus recursos para as futuras gerações considerando os recursos naturais como patrimônio comum.

Palavras-chave: Recursos Naturais, Assentamentos, Patrimônio Ambiental.

*Aluno de iniciação científica CNPq - Programa de Mestrado em Desenvolvimento Regional e Meio Ambiente da Uniara.

**Docentes e pesquisadores do Programa de Mestrado em Desenvolvimento Regional e Meio Ambiente da Uniara. 


\section{SISTEMAS DE CERTIFICAÇÃO NAAGRICULTURA}

CAVALLARI, Luis Felipe*; PAULINO, Sônia Regina**

Nas últimas duas décadas, vários sistemas de certificação têm sido implantados nas propriedades rurais e na agroindústria. Os objetivos do trabalho são identificar e descrever sistemas de certificação em disseminação na agricultura brasileira. Foi realizado estudo bibliográfico e documental com o levantamento de dados qualitativos. Foram considerados sistemas de certificação voluntária realizada por terceira parte, que incorporam a dimensão ambiental em seus princípios, tendo como referência padrões estabelecidos por organizações privadas. Verifica-se a adoção de sistemas de certificação voltados à melhoria do desempenho social e ecológico dos sistemas produtivos e, mais recentemente, a disseminação da certificação calcada na conformidade de procedimentos. Os sistemas de certificação agrícola identificados são: orgânica, comércio justo, Rainforest Alliance, Forest Stewardship Council, ISO 14001, GlobalGAP e certificação participativa. A implantação de sistemas de certificação abre novas perspectivas, considerando os indicadores, presentes em seus respectivos protocolos, para a análise e discussão das condições de sustentabilidade da agricultura, com base na identificação de impactos positivos e negativos.

Palavras-chave: Sistemas de Certificação, Agroindústria.

\section{FORNECEDORES DE PRODUTOS CERTIFICADOS EM CADEIAS}

\section{GLOBAIS DE VALOR}

SCIENCIA, Israel*; PAULINO, Sônia Regina**

O objetivo do trabalho é analisar as mudanças incidentes sobre os fornecedores de produtos agrícolas in natura certificados para mercados globais. Foi realizado estudo bibliográfico e documental, com levantamento de dados qualitativos sobre a atuação de duas empresas, fornecedoras de abacate e de carne bovina com certificação GLOBALGAP. As análises sobre mudanças nos requerimentos de qualidade dos produtos se voltam para consumidores e grandes compradores que estabelecem os parâmetros para os produtos que irão adquirir. Em se tratando de cadeias globais de valor, os dois elos da cadeia mencionados estão localizados nos países desenvolvidos. É preciso avançar no entendimento do papel dos participantes das cadeias produtivas globalizadas localizados nos países fornecedores. Em busca de inserção em mercados globalizados, fornecedores de produtos agrícolas in natura se colocam no centro de uma teia local de relacionamentos envolvendo organizações certificadoras, produtores rurais, fontes de conhecimento técnico e científico para a produção agrícola e agroindustrial, fornecedores de embalagens, fornecedores de pallets.

Palavras-chave: GLOBALGAP, Certificação.
*Aluno do Programa de Mestrado em Desenvolvimento Regional e Meio Ambiente do Centro Universitário de Araraquara - Uniara.

**Docente da Escola de Artes, Ciências e Humanidades - USP/SP e do Programa de Mestrado em Desenvolvimento Regional e Meio Ambiente do Centro Universitário de Araraquara - Uniara. 